\title{
Description of fifteen new species of the Hypoxys balteatus species group (Hemiptera: Heteroptera: Pentatomidae)
}

\author{
Maria Thayane S. MENDONCA ${ }^{1)}$, Benedito M. NUNES ${ }^{2)} \&$ Jose Antonio M. FERNANDES ${ }^{3)}$ \\ Universidade Federal do Pará, Instituto de Ciências Biológicas, Av. Augusto Correa \#1 66075-110, Belém, Pará, Brazil; \\ 1) e-mail: thaymendonca4@gmail.com \\ 2) e-mail: beneditomn@gmail.com \\ ${ }^{22}$ e-mail: joseamf@ufpa.br (corresponding author)
}

\author{
Accepted: \\ $2^{\text {nd }}$ June 2021 \\ Published online: \\ $7^{\text {th }}$ August 2021
}

\begin{abstract}
Hypoxys Amyot \& Serville, 1843 (Hemiptera: Heteroptera: Pentatomidae: Edessinae), for a long time considered a synonym or subgenus of Edessa Fabricius, 1803, was recently revised and reinstated to the generic rank. This genus comprises 17 described species divided in four species groups: $H$. quadridens, $H$. oxyacanthus, $H$. triangularis, and $H$. balteatus species group. Also, there is a large number of new species yet to be described. The $H$. balteatus species group is diagnosed by: pronotum with posterior stripe smoky brown to black with black punctures within, sometimes these punctures are surrounded by small dark spots; punctures of the pronotal disc smaller and paler than those of the posterior stripe; anterolateral margin of pronotum yellow; anterior half of scutellum with punctures large, sparse, and also on dark spots; connexivum uniformly green, without dark spots; thorax ventrally with two pairs of brown to black rounded spots; apex of pseudosutures with black to brown round spots. This species group included so far only H. balteatus (Walker, 1868). Here we describe and assign 15 new species to this group: H. amyoti sp. nov. (Suriname: Powakka; French Guiana), H. aspilogaster sp. nov. (Brazil: Minas Gerais, Espírito Santo and Rio de Janeiro), H. belenensis sp. nov. (Brazil: Pará), H. bergrothi sp. nov. (Venezuela: Amazonas; French Guiana: Saint-Elie), H. breddini sp. nov. (Bolivia: Santa Cruz and San Carlos), H. caquetensis sp. nov. (Colombia: Caquetá), H. favachae sp. nov. (Suriname: Sipaliwini; Brazil: Amapá and Pará), H. gaucho sp. nov. (Brazil: Rio Grande do Sul), H. hyalinofasciatus sp. nov. (Ecuador: Sucumbíos), H. immaculatus sp. nov. (Bolivia: Beni), H. nigroantennatus sp. nov. (French Guiana: Roura), H. santarensis sp. nov. (Brazil: Pará), H. servillei sp. nov. (Brazil: Mato Grosso and Goiás), H. stysi sp. nov. (Suriname: Coronie, Sipaliwini; French Guiana: Cayenne), and H. venustus sp. nov. (Bolivia: Cochabamba). Descriptions, measurements, photos of dorsal and ventral view of each species, and of external genitalia of both sexes, an identification key, and distributional maps are presented.
\end{abstract}

Key words. Hemiptera, Heteroptera, Pentatomidae, Edessinae, stink bugs, new species, taxonomy, Neotropical Region

Zoobank: http://zoobank.org/urn:lsid:zoobank.org:pub:DD0F4CB0-2288-4285-9FE2-6843F4952967

(C) 2021 The Authors. This work is licensed under the Creative Commons Attribution-NonCommercial-NoDerivs 3.0 Licence.

\section{Introduction}

Genus Edessa was proposed by FABRICIUs (1803) to include 43 different species. In the ensuing decades and centuries, a number of workers have added and removed species to and from the genus without adjusting the generic description. Thus, the genus has become somewhat of a dumping ground for many varied species, many of which may belong in other related genera. It has become imperative that the generic limits of Edessa (including its subgenera and species groups) and related genera be redefined, and their relationships be determined. АмYOт \& SeRville (1843) created Edessidés to include Edessa, Brachystethus Laporte, 1832 and five new genera: Aceratodes, Dorypleura, Hypoxys, Peromatus, and Pygoda, all 
based on species removed from Edessa, plus several genera belonging to Tessaratomidae and Dinidoridae at present. A few changes were made by different authors after this work, mainly describing species and less frequently synonymizing genera with Edessa, which enlarged the limits of this genus (part of this confusing history can be seen in SANTOS et al. 2015; NunEs et al 2019, 2020). STÅL (1872) was the first attempting to organize the genus Edessa in species groups, but he did not succeed completely because several species were listed outside these groups.

In the last 30 years the huge morphological diversity of Edessa represented by more than 300 described species and about the same number of new species (Fernandes, pers. data) has been revised. During this time groups of species with diagnostic characteristics have been selected and described. Since then, seven genera have been described: Mediocampus Thomas 1994, Doesburgedessa Fernandes, 2010, Paraedessa Silva \& Fernandes, 2013, Grammedessa Correia \& Fernandes, 2016, Plagaedessa Almeida \& Fernandes, 2018, Anisoedessa Nunes \& Fernandes, 2019, and Graziaedessa Eger, 2021. Three subgenera of Edessa have been raised to genus level: Ascra Say, 1832 (SANTOS et al. 2015), Pygoda (Fernandes et al. 2018), and Hypoxys Amyot \& Serville, 1843 (NunEs et al. 2020). Besides, 10 groups of species within Edessa have been established: Edessa dolichocera (FernANDES \& Doesburg 2000a); E. beckeri (FERNANDES \& DoESBURG 2000b); E. cervus (Fernandes \& Doesburg 2000c); E. collaris (Fernandes et al. 2001); E. rufomarginata (Ely E Silva et al. 2006); E. metallica (FERNANDES \& CAMPOS 2011); E. caldaria (Da Silva \& Fernandes 2012); E. pudibunda (Santos et al. 2014); E. viridula (NAscimento et al. 2017); E. stalii (CAMPos et al. 2020), and E. ovina species group (FERNANDES \& SILVA 2021).

Hypoxys was proposed by Amyot \& SeRVILle (1843) to accommodate Edessa quadridens Fabricius, 1803. This genus was recently reinstated and revised by NUNES et al. (2020). In the same work, Hypoxys was divided in four groups of species (H. quadridens, H. triangularis, $H$. oxyacanthus, and $H$. balteatus species group) based on morphological characteristics, with the intention to organize the large number of known but not yet described species of Hypoxys. The H. balteatus species group was proposed for a single species: Hypoxys balteatus (Walker, 1868), but the number of undescribed species belonging to this group is considerably higher. NunEs et al. (2020) diagnosed all groups of species and presented a key to the groups and known species.

This paper presents the descriptions of fifteen new species of Hypoxys belonging to the H. balteatus group, as well as a complement for the diagnosis of the group, and an identification key.

\section{Material and methods}

For this study, 41 specimens from the following institutions and private collections were analyzed:

FMNH Field Museum of Natural History, Chicago, United States; IRSB Institut Royal des Sciences Naturelles de Belgique, Brussels, Belgium;
JEE Joseph E. Eger's Collection, Tampa, United States;

MNHN Muséum National d'Histoire Naturelle, Paris, France;

MNRJ Museu Nacional, Rio de Janeiro, Brazil;

MPEG Museu Paraense Emílio Goeldi, Pará, Brazil;

MZUSP Museu de Zoologia da Universidade de São Paulo, São Paulo, Brazil;

RMNH Naturalis, Leiden, The Netherlands;

UFES Universidade Federal do Espírito Santo, Vitória, Brazil;

UFMT Universidade Federal do Mato Grosso, Mato Grosso, Brazil;

UFRGS Universidade Federal do Rio Grande do Sul, Rio Grande do Sul, Brazil;

USNM National Museum of Natural History, Smithsonian Institution, Washington, DC, United States;

ZMUC Natural History Museum of Denmark, University of Copenhagen, Copenhagen, Denmark;

ZSMC Zoologische Staatssammlung München, Munich, Germany.

The descriptions and terminology used follows NunES et al. (2020) for general body description, Dupuis (1970) for the male genitalia, ZHOU \& RÉDEI (2020) for external female genitalia and KMENT \& ViLímoví (2010) for the scent gland apparatus. The pygophore was removed with the aid of Mr. Muscle ${ }^{\circledR}$ kitchen cleaner that quickly hydrates tissues and dissolves the substances that keep the pygophore stuck inside the abdomen. The same product was also used to clean the whole specimen selected to be photographed, removing grease and dirt from the surface. This product does not change the color of the specimen cleaned. The measurements were made using an eyepiece graticule scale attached to a Zeiss Discovery V8 stereomicroscope (total length, length of head, width of head, length of antennomeres, length of pronotum, width of pronotum, length of scutellum, width of scutellum, width of abdomen). Measurements are presented in millimeters; the numbers in parentheses are the minimum and maximum measures obtained. Images were taken using a Leica DFC 450 camera connected to a Leica M205A stereomicroscope and stacked with Leica auto montage software (LAS software). The images were edited using Adobe Photoshop ${ }^{\circledR}$. Maps were made in QGIS (2016).

\section{Results}

\section{Hypoxys balteatus species group}

Diagnosis. Pronotum with posterior stripe, smoky brown to black, with black punctures, sometimes punctures on small dark spots (Figs 5A,C,E); posterolateral angles somewhat prominent, smaller than eye width (Fig. 1A). Anterolateral margin of pronotum yellow. Anterior half of scutellum with large, sparse punctures on dark spots (Figs 3A,C,E). Connexivum uniformly green, without dark spots (Figs 5A,E), except for $H$. nigroantennatus sp. nov. and $H$. bergrothi sp. nov. Body ventrally green, yellow medially, sometimes with narrow yellow transverse stripes; brown to black round spots on thorax (meso- and metapleura) and pseudosutures (Figs 5B,D), except for H. immaculatus sp. nov. (Fig. 4B) and H. aspilogaster sp. nov. (Fig. 1B). Parameres almost straight in dorsal view, but never strongly curved laterally like in other species of Hypoxys (Fig. 7A - green dash). Ventral rim of pygophore with expansions (Fig. 6B) developed, acuminate, and triangular in cross section (Figs 16B-D); expansions shallowly excavated 

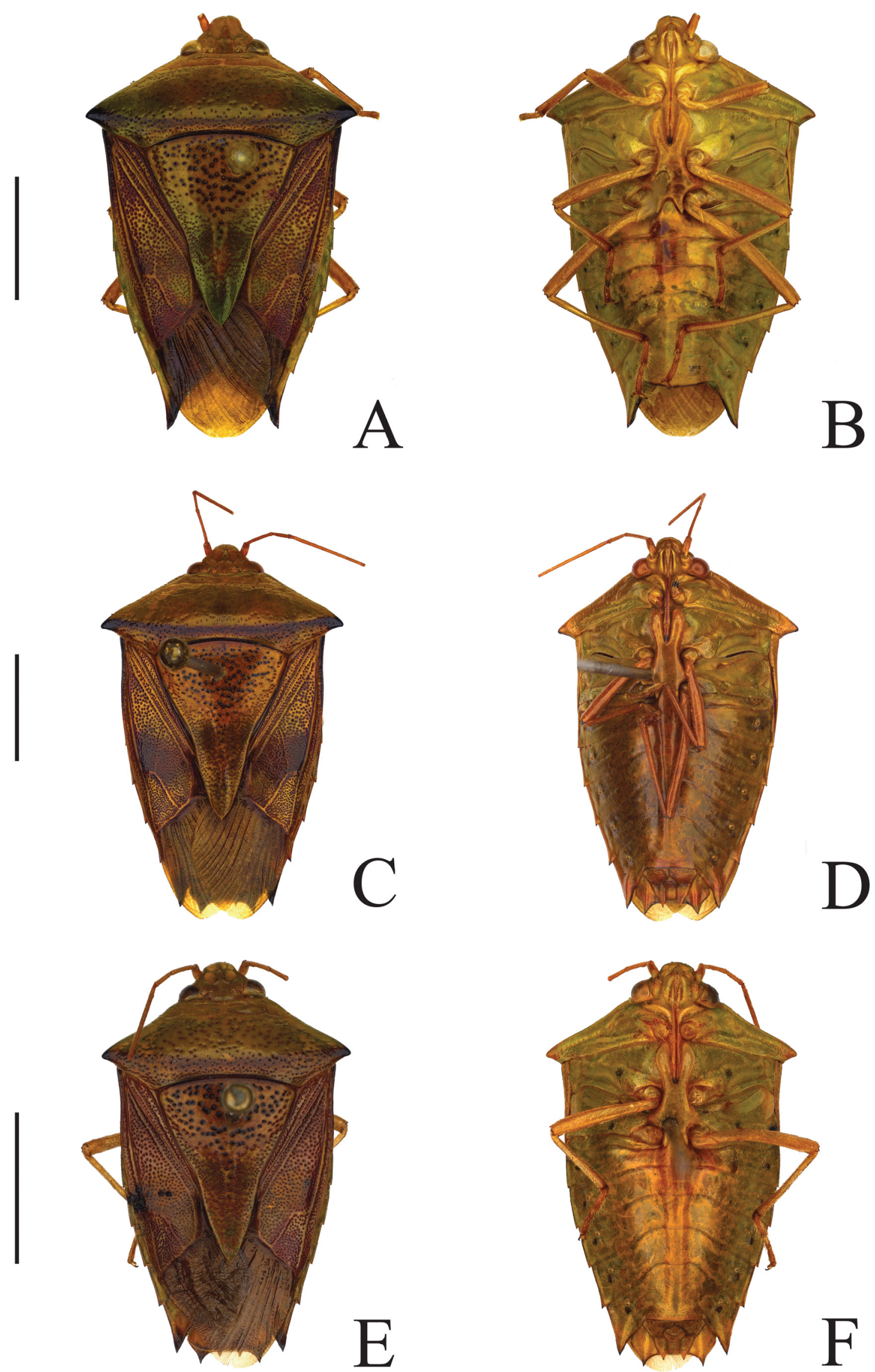

Figs 1A-F. Dorsal and ventral surface. A-B - Hypoxys amyoti sp. nov.; C-D - Hypoxys aspilogaster sp. nov.; E-F - Hypoxys belenensis sp. nov. Scale bars $=5 \mathrm{~mm}$. 

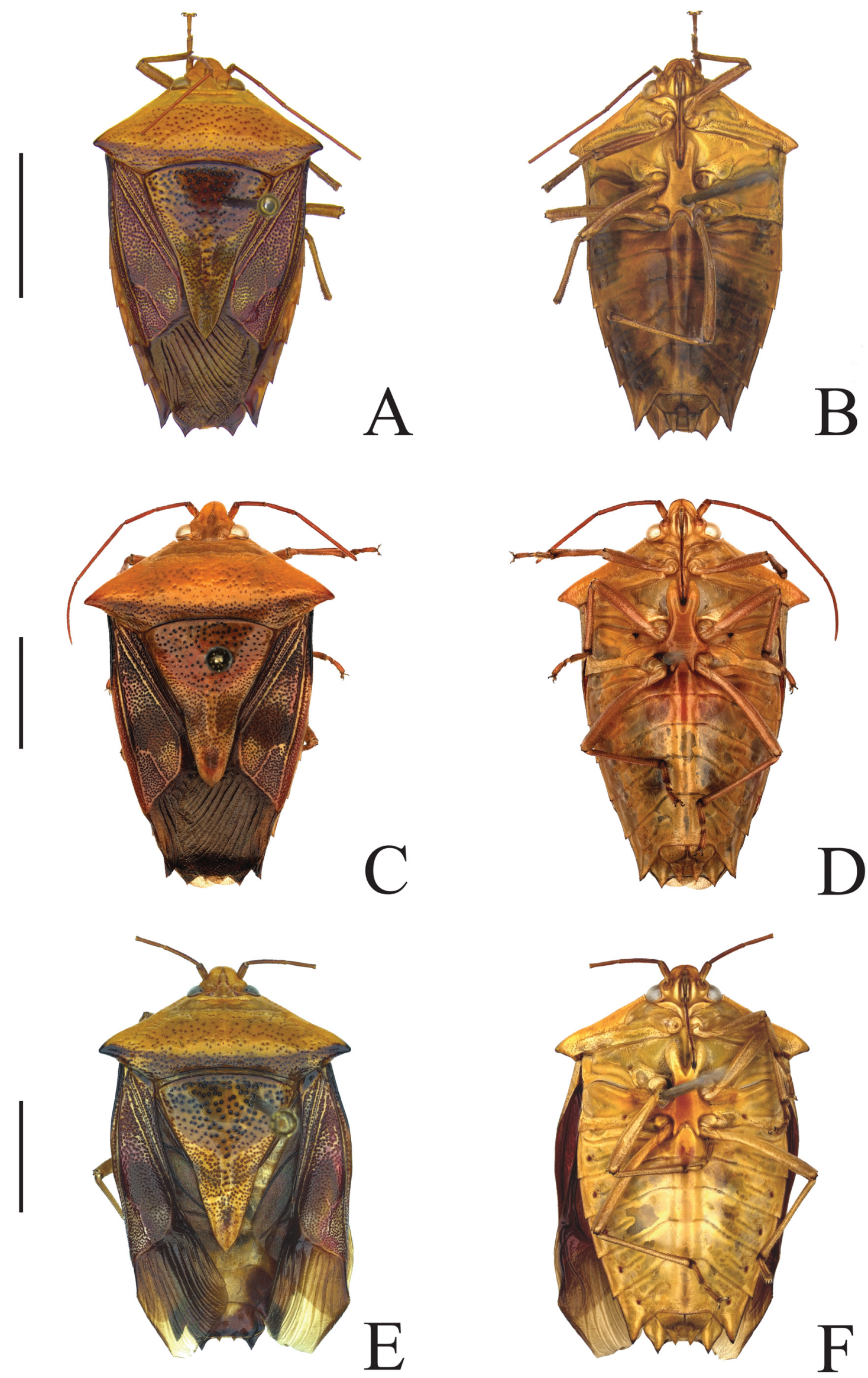

Figs 2A-F. Dorsal and ventral surface. A-B - Hypoxys bergrothi sp. nov.; C-D - Hypoxys breddini sp. nov.; E-F - Hypoxys caquetensis sp. nov. Scale bars $=5 \mathrm{~mm}$. 


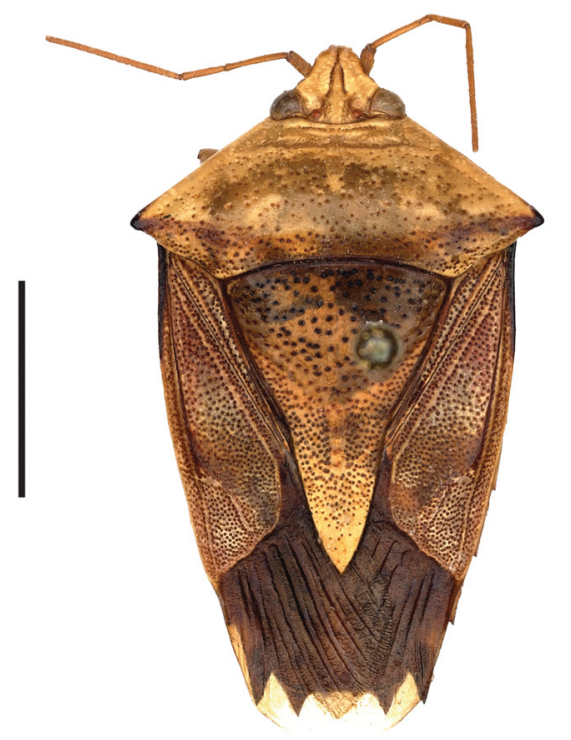

$\mathrm{A}$
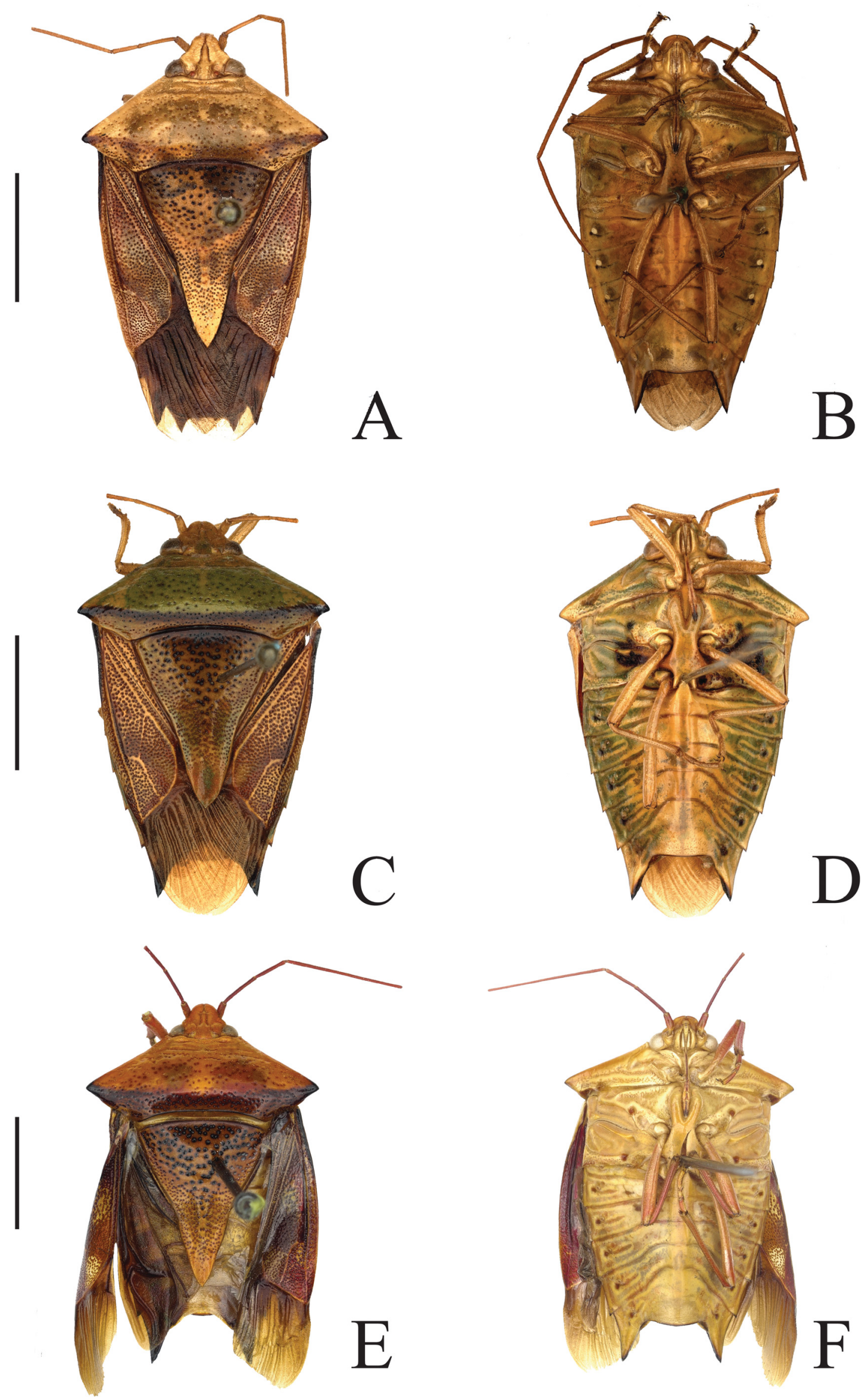

Figs 3A-F. Dorsal and ventral surface. A-B - Hypoxys favachae sp. nov.; C-D - Hypoxys gaucho sp. nov.; E-F - Hypoxys hyalinofasciatus sp. nov. Scale bars $=5 \mathrm{~mm}$. 

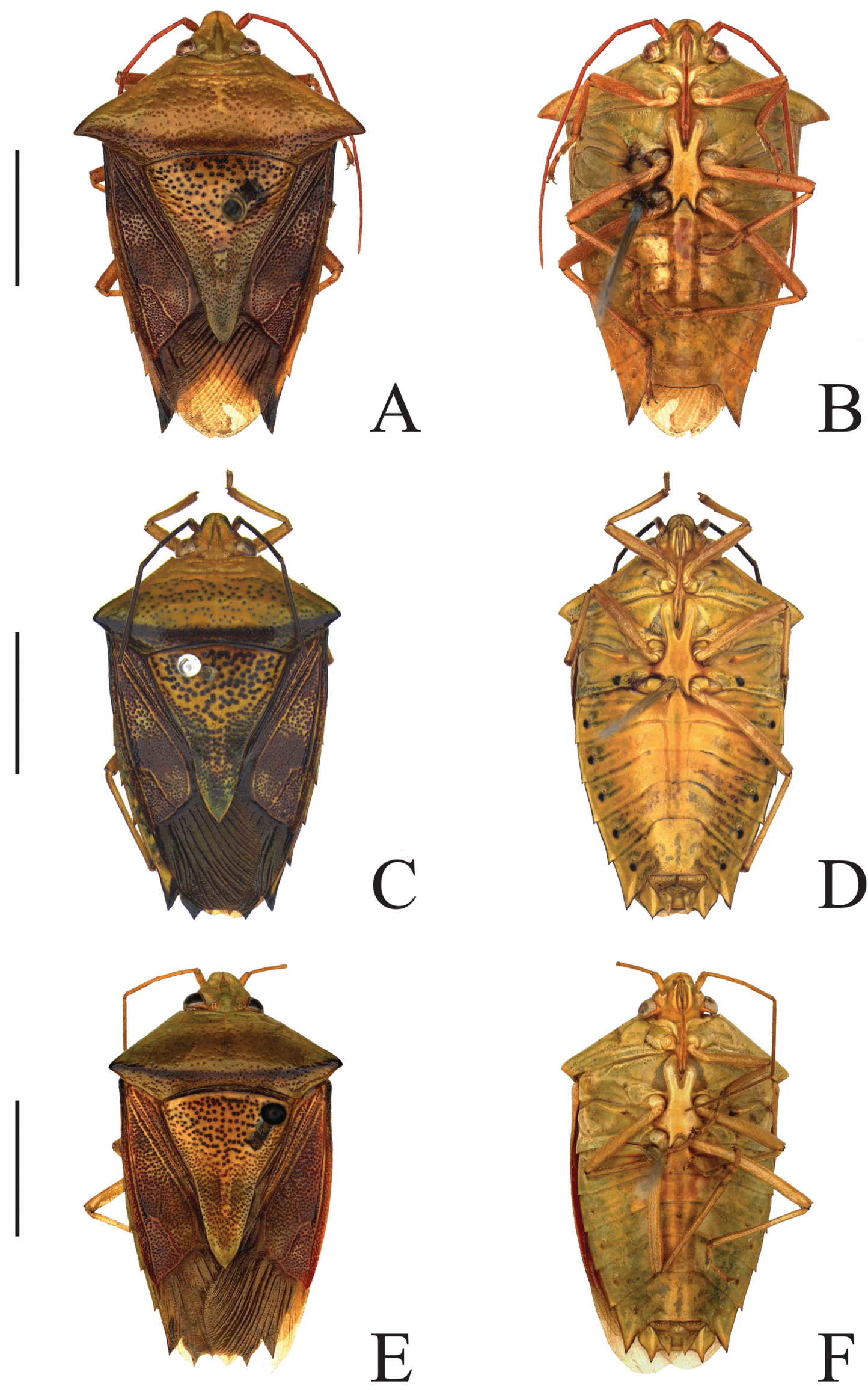

Figs 4A-F. Dorsal and ventral surface. A-B - Hypoxys immaculatus sp. nov.; C-D - Hypoxys nigroantennatus sp. nov.; E-F - Hypoxys santarensis sp. nov. Scale bars $=5 \mathrm{~mm}$. 

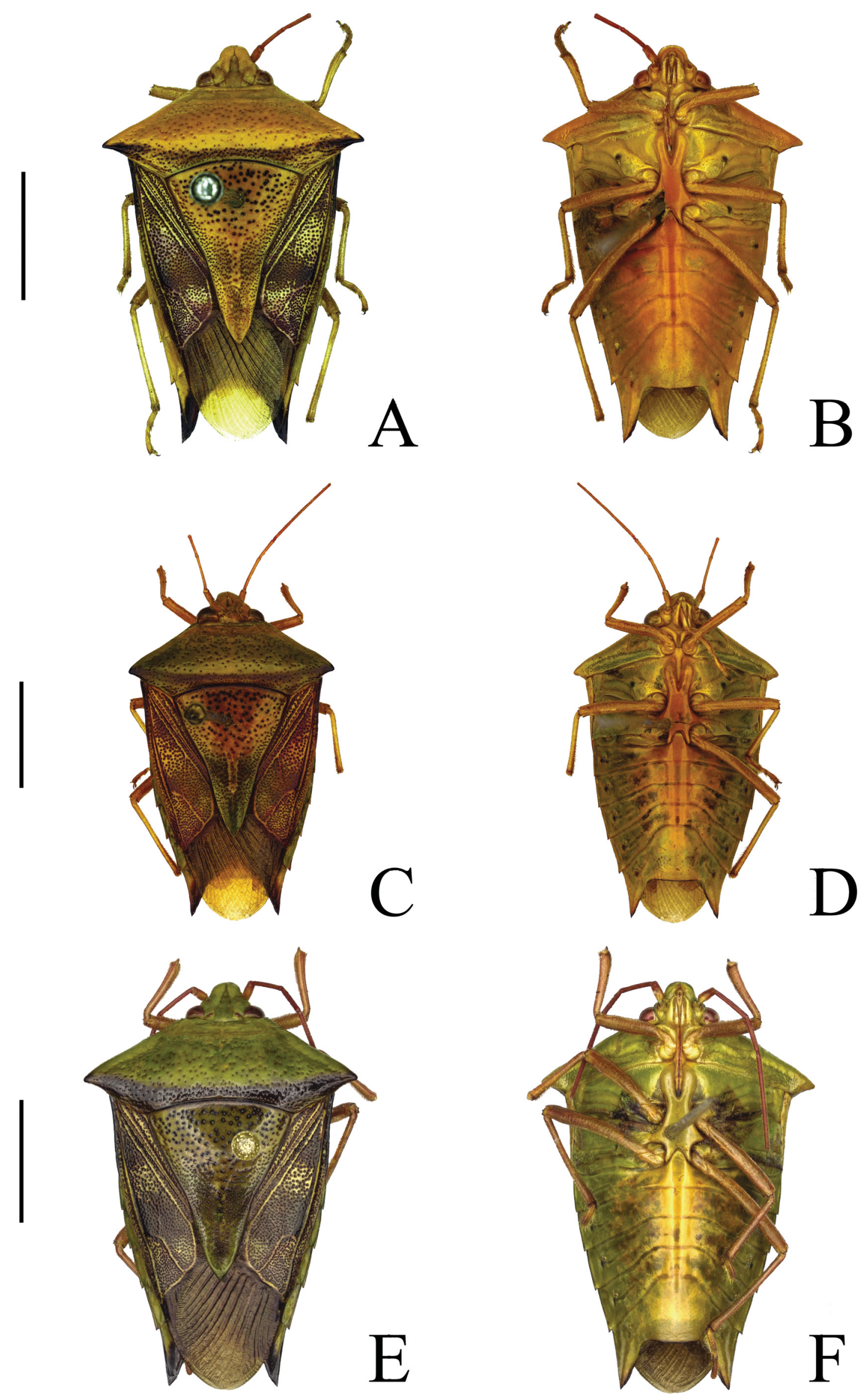

Figs 5A-F. Dorsal and ventral surface. A-B - Hypoxys servillei sp. nov.; C-D - Hypoxys stysi sp. nov.; E-F - Hypoxys venustus sp. nov. Scale bars $=5 \mathrm{~mm}$. 
ventrolaterally (Fig. 19C), except for H. santarensis sp. nov. Valvifers 8 with distal margin projected caudally, posterolateral angle armed with small tooth projected over laterotergites 9 (Fig. 16E).

Redescription. Head. Mandibular plates and clypeus without black marks (except $H$. nigroantennatus sp. nov.). Thorax. Cicatrices of pronotum smooth. Scutellum with rare, minute punctures apically, some species have spots that resemble punctuation (Figs 1C, 2A). Evaporatorium and ventral surface of thorax concolorous. Abdomen. Connexivum with shallow punctures, punctures concolorous with abdomen. Distal half or less of segment VII black. Without dark transversal stripes ventrally. Male genitalia (Figs 6A-D). Bottom of ventral rim excavation with tiny fold. Female genitalia (Fig. 6E). Distal margin of laterotergites 8 and 9 black.

Distribution (Fig. 21). Venezuela: Amazonas. Colombia: Caquetá. Suriname: Powakka, Sipaliwini, Coronie. French Guiana: Saint-Elie, Cayenne. Brazil: Amapá, Pará, Mato Grosso, Goiás, Minas Gerais, Espírito Santo, Rio de Janeiro, Rio Grande do Sul. Ecuador: Sucumbíos. Bolivia: Santa Cruz, San Carlos, Beni, Cochabamba (this paper).

\section{Key to species of the Hypoxys balteatus group}

1 Antennae black (Figs 4C,D); margin of mandibular plates black (Figs 4C,D).

H. nigroantennatus sp. nov.

- Antennae yellow to reddish brown (Figs 5E,F); margin of mandibular plates never black (Figs 5E,F)................................................................. 2

2 Female. .................................................................. 3

- Male. ................................................................. 12

3 Posterior margin of valvifers 8 slightly projected caudally, posterolateral angle not reaching middle of valvifers 9 (Figs 10E, 17E). ................................ 4

- Posterior margin of valvifers 8 projected caudally, posterolateral angle exceeding middle of valvifers 9 (Figs 6E, 9A, 18E).

4 Posterior angles of valvifers 8 not acuminate, barely reaching base of valvifers 9 (Fig. 17E). ............... 5

- Posterior angles of valvifers 8 acuminate, almost reaching middle of valvifers 9 (Fig. 10E).

H. breddini sp. nov.

5 Inner margin of valvifers 8 widely open, valvulae 8 exposed (Fig. 17E). ........... H. santarensis sp. nov.

- Inner margin of valvifers 8 shallowly excavated, valvulae 8 barely exposed (see Nunes et al. 2020: Fig. 17C). H. balteatus (Walker, 1868)

6 Valvifers 8 overlapping lateral margin of valvifers 9, excavation of valvifers 8 narrow (Fig. 9A)

H. bergrothi sp. nov.

- Valvifers 8 not overlapping lateral margin of valvifers 9, excavation of valvifers 8 broad (Figs 6E, 8A, 14E).

7 Bottom of the excavation of valvifers 8 convex (Figs $6 \mathrm{E}, 19 \mathrm{E})$.

- Bottom of the excavation of valvifers 8 concave (Figs 8A, 11A).
8 Laterotergites 9 reaching or just surpassing the level of the angles of abdominal segment VII, and clearly surpassing the band connecting laterotergites 8 (Fig. $6 \mathrm{E})$. H. amyoti sp. nov.

- Laterotergites 9 below the level of the angles of abdominal segment VII, and just surpassing the band connecting laterotergites 8 (Fig. 19E).

H. stysi sp. nov.

9 Posterior margin of each valvifers 8 almost straight; level with distal margin of valvifers 9 (Fig. 11A). ....

H. caquetensis sp. nov.

- Posterior margin of each valvifers 8 concave or slanting; never reaching posterior margin of valvifers 9 (Fig. 8A). 10

10 Apices of abdominal segments VII almost level with apices of laterotergites 8 and clearly above the level of laterotergites 9 (Figs 12E, 18E). .. 11

- Apices of abdominal segments VII clearly below the level of laterotergites 8 and level with laterotergites 9 (Fig. 8A).

H. belenensis sp. nov.

11 Valvifers 8 unicolorous, without contrasting black punctures; distal spine of each laterotergite 8 clearly wider at base than long (considering the line of the band connecting laterotergites 8) (Fig. 18E).

H. servillei sp. nov.

- Valvifers 8 with inner margin dark brown and contrasting black punctures; distal spine of each laterotergite 8 almost as long as wide at base (considering the line of the band connecting laterotergites 8) (Fig. 12E). .... H. favachae sp. nov.

12 Thorax without brown spots (Figs 1D, 4B); pseudosutures without brown spots on outer lateral apex (Figs 1B, D).

- Thorax with four brown spots on meso- and metapleura (Figs 10F, 16F); pseudosutures with brown spots on outer lateral apex (Figs 1F, 3F)............................ 14

13 Superior process of genital cup with inner part entire (Figs 15C,D); expansions of ventral rim acuminate, just passing level of posterolateral angle of pygophore (Figs 15A,B).

H. immaculatus sp. nov.

- Superior process of genital cup with inner part bifid (Figs 7C,D); expansions of ventral rim long, narrow and clearly surpassing posterolateral angle of pygophore (Figs 7A,B). ..... H. aspilogaster sp. nov.

14 Dorsal rim of the pygophore with a lateral projection (Fig. 17A, arrow).............................................. 15

- Dorsal rim of the pygophore without a lateral projection (Fig. 10A). ......................................... 17

15 Ventral rim expansion without a lateral excavation (Fig. 17B); superior process of genital cup undivided (Fig. 17D). H. santarensis sp. nov.

- Ventral rim expansion with a lateral excavation (Fig. 19C, arrow), superior process of genital cup bifurcated (Figs 13D, 19D). ............................. 16

16 Dorsal margin of paramere medially concave (Figs 13C,D); expansion of ventral rim long and narrow (Figs 13A,B); superior process of genital cup large with a median carina, arms of the bifurcation of different lengths (Figs 13C,D). ... H. gaucho sp. nov. 
- Dorsal margin of paramere sinuous (Figs 19C,D); expansion of ventral rim short and broad (Fig. 19B); superior process of genital cup narrow and concave, arms of the bifurcation similar in length (Figs 19C,D).

H. stysi sp. nov.

17 Superior process of genital cup lateral, wide, reaching or almost reaching posterolateral angles of pygophore (Figs 6A, 12A, 20A). .. 18

- Superior process of genital cup short and closer to proctiger than to posterolateral angles of pygophore (Figs 10C,D).

H. breddini sp. nov.

18 Superior process of genital cup with inner part bifurcated (Figs 6D, 12D). ................................. 19

- Superior process of genital cup with inner part ventrally curved and not bifurcated (Fig. 18D). ... 20

19 Dorsal rim separated from proctiger (Figs 6C,D); anterior lobe of paramere subrectangular (Figs $6 \mathrm{C}, \mathrm{D})$; superior process of genital cup narrow and long, reaching the apex of posterolateral angle of pygophore (Figs 6A,B).

H. amyoti sp. nov.

- Dorsal rim in contact with proctiger (Figs 12C,D); anterior lobe of paramere triangular (Figs 12C,D green circle); superior process of genital cup broad and short, not reaching the apex of posterolateral angle of pygophore (Fig. 12A)

H. favachae sp. nov.

20 Dorsal margin of paramere slightly concave (Figs 14C,D). ....................... H. hyalinofasciatus sp. nov. Dorsal margin of paramere sinuous (Figs 18C,D, 20C,D). 21

21 Posterior face of proctiger rounded to subpentagonal (Figs 18C,D); expansions of ventral rim rounded distally in ventral view (Fig. 18B).

H. servillei sp. nov.

- Posterior face of proctiger triangular (Figs 20C,D); expansions of ventral rim acuminate in ventral view (Fig. 20B).

H. venustus sp. nov.

\section{Hypoxys amyoti sp. nov. \\ (Figs 1A-B, 6A-F, 21A)}

Material examined. Holotype: $\hat{\jmath}$, FRENCH GUIANA: 1899 / R. Oberthur BAR coll. (MNHN). PARATYPES: SURINAME: PowaKKa: o, 12.iv.1972 / G. F. Mees (RMNH); + , same data holotype (MNHN).

Diagnosis. Antennae brown. Antennomere II longer than III. Smoky stripe on pronotum not reaching posterior margin of pronotum. Thoracic and abdominal pleurites and sternites with black spots (Fig. 1B). Anterior excavation of metasternal process harboring fourth and almost whole third rostral segment (Fig. 6F). Male genitalia. Pygophore (Figs 6A-D). Posterolateral angles developed, bent inwards, acuminate (Fig. 6A). Superior process of genital cup trilobate, curved, elongated, parallel to dorsal rim and almost reaching apex of posterolateral angle; inner part bifid, forming two small lobes; outer part tapering (Figs 6A,C,D). Paramere with two lobes; anterior lobe square, curved upwards; lateral lobe rounded (Figs $6 C, D)$. Proctiger with dense crown of setae; posterior face subpentagonal and short (Figs 6C,D). Expansions of ventral rim acuminate, broadly excavated ventrolaterally, with brown spot dorsally; barely surpassing level of posterolateral angles (Figs 6A,B). Female genitalia. Genital plates (Fig. 6E). Posterior margin of each valvifer 8 with dentiform posterolateral angles, directed posteriorly; inner angles dentiform, reaching valvifers 9; imaginary line tangent to posterolateral angles reaching distal margin of valvifers 9; inner margin slightly projected posteriorly, leaving bottom of excavation convex; excavation U-shaped. Valvulae 8 barely visible. Apices of laterotergites 8 clearly above level of apices of abdominal segment VII. Laterotergites 9 surpassing band connecting laterotergites 8 ; apices just passing imaginary line tangent to apices of abdominal segment VII.

Measurements $(\mathrm{n}=3$; mm). Total length 15.9-16.3; head length 1.6-2.0; head width 3.4-3.5; pronotum width 10.0-10.2; abdomen width 8.1-8.2; length of antennomeres: I - 0.6-0.9; II - 1.6-1.7; III - 0.9-1.1; IV - 3.5-3.7; $\mathrm{V}-3.9$; scutellum length 6.8-7.2; scutellum width 5.6-5.8; pronotum length 3.3-3.6.

Differential diagnosis. This species resembles $H$. aspilogaster sp. nov. and $H$. stysi sp. nov. in the shape of the trilobate superior process of genital cup, but the shape of the paramere and the posterior face of the proctiger separate them. The female genitalia of $H$. amyoti sp. nov. and $H$. stysi sp. nov. are very similar showing the bottom of the excavation of valvifers 8 convex. Both species can be hardly separated using only females; the length of laterotergite 9 seems to be the only character with visible difference.

Etymology. Named after Charles Jean-Baptiste Amyot (1799-1866), the great French entomologist and one of the first researchers dedicated to the study of Heteroptera. Distribution (Fig. 21A). Suriname: Powakka; French Guiana.

\section{Hypoxys aspilogaster sp. nov. (Figs 1C-D, 7A-F, 21A)}

Material examined. Holotype: $\curvearrowright$, BRAZIL: Rio de JANEIRo: Parna [Parque Nacional] / Serra dos Órgãos, Teresopólis / 1956 / Zajciv col. (MNRJ). PARATYPES: BRAZIL: Minas Gerais: + , João Monlevade, Itabira / 17.ii.1939 / P. Balch-Bath (ZMUC). Espírito SAnto: $\hat{\jmath}$, Reserva florestal CVRD, Linhares / 17.vi.1987 / J. S. Santos (UFES);

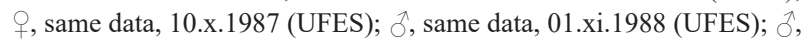
same data, 24.viii.1989; (UFRGS); 9 , Fibria, Linhares (UFES); + , same data (UFRGS); $\hat{\jmath}$, Parque Sooretama, Linhares / D. Zajciv leg. (MNRJ).

Diagnosis. Antennae brown. Antennomere II longer than III. Pronotum with smoky stripe not reaching posterior margin. Thoracic and abdominal pleurites and sternites without black spots (Fig. 1D). Anterior excavation of metasternal process harboring fourth and third rostral segment (Fig. 7F). Male genitalia. Pygophore (Figs 7A-D). Posterolateral angles developed, bent inwards (Fig. 7A). Superior process of genital cup trilobate (inner part notched, forming two long, digitiform lobes; outer part tapering), almost straight, elongated, parallel to dorsal rim, and almost reaching posterolateral angle (Figs 7A,C,D). Paramere with two lobes; anterior lobe narrow and triangular, directed to base of proctiger; lateral lobe large, triangular and straight (Figs 7C,D). Proctiger with narrow tufts of setae on lateral excavation; posterior face triangular (Figs 7C,D). Ventral rim with expansions developed, distally rounded, vent- 

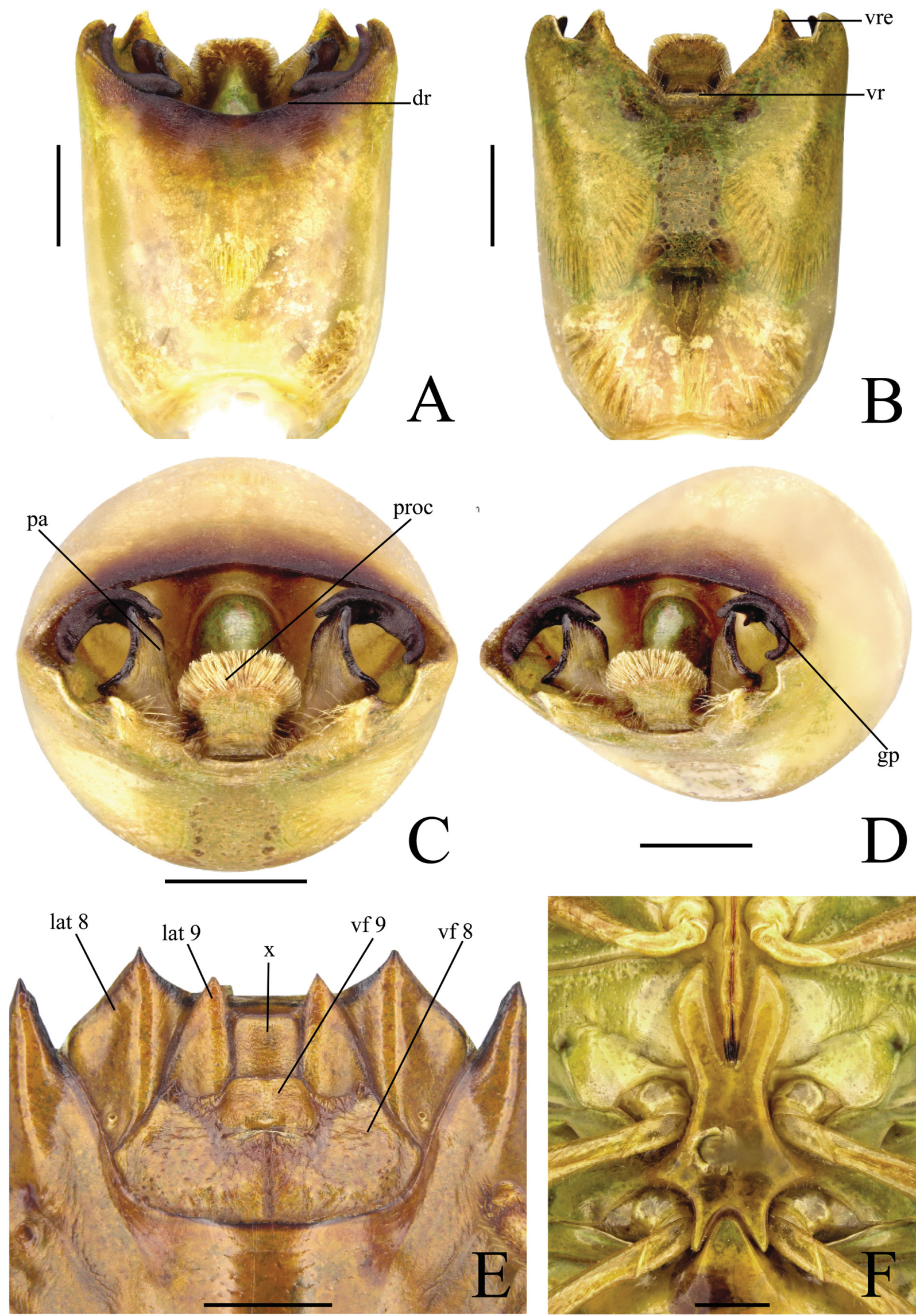

Figs 6A-F. Hypoxys amyoti sp. nov. A-D - pygophore in dorsal, ventral, posterior and posterolateral view, respectively; E-genital plates; F - metasternal process. Abbteviations: $\mathrm{dr}$ - dorsal rim; gp - superior process of the genital cup; lat 8 - laterotergites 8 ; lat 9 - laterotergites 9 ; pa - parameres; proc proctiger; vf 8 - valvifers 8 ; vf 9 - valvifers 9 ; vr - ventral rim; vre - ventral rim expansions; $\mathrm{x}$ - tenth segment. Scale bars $=1 \mathrm{~mm}$. 

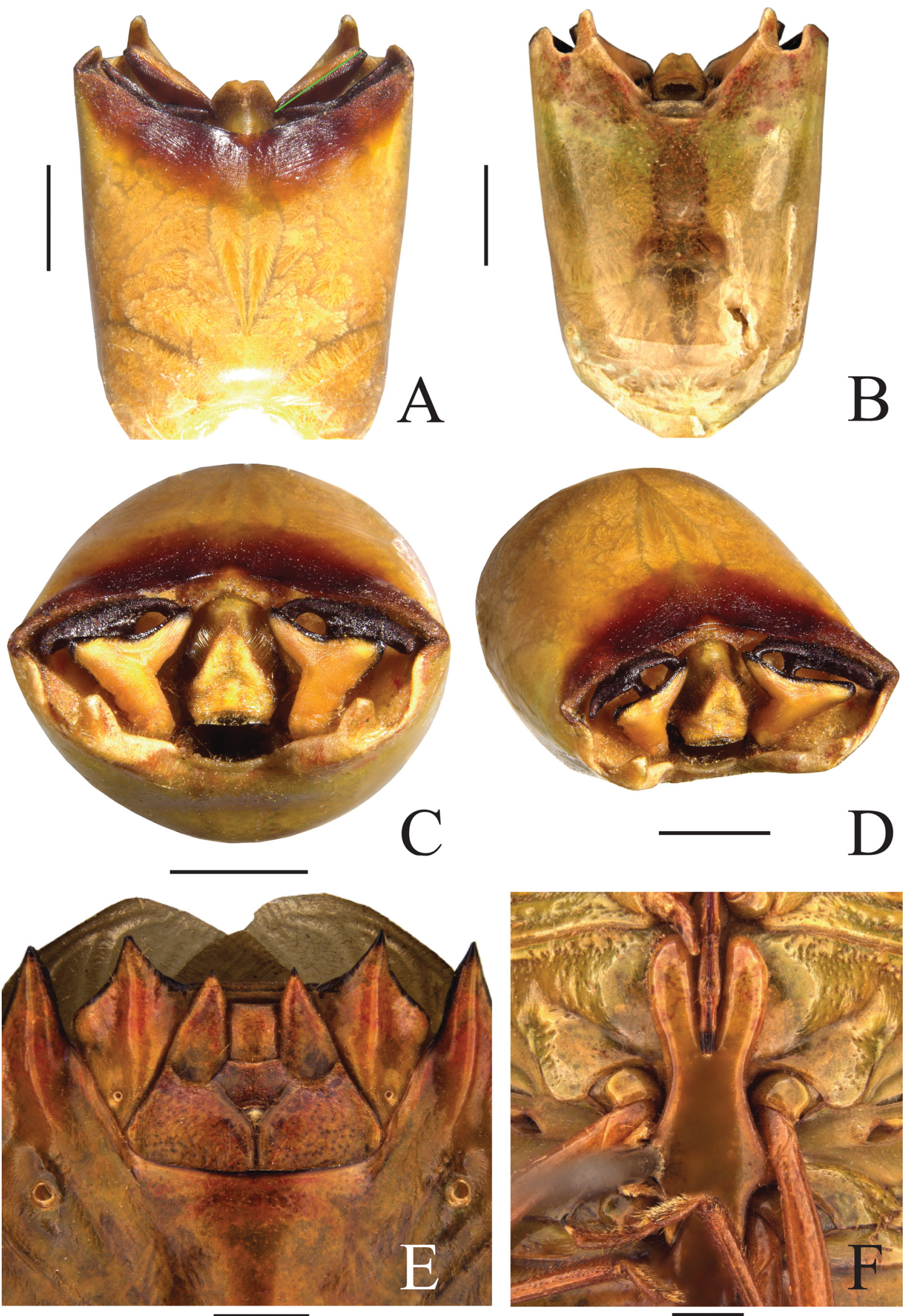

Figs 7A-F. Hypoxys aspilogaster sp. nov. A-D - pygophore in dorsal, ventral, posterior and posterolateral view, respectively; E - genital plates; F metasternal process. Green line in Fig. A indicates that paramere is straight. Scale bars $=1 \mathrm{~mm}$. 
rolateral side broadly excavated, dorsal side with brown spot; clearly surpassing level of posterolateral angles (Fig. 7B). Female genitalia. Genital plates (Fig. 7E). Valvifers 8 posterior margin with posterolateral angles dentiform and posteriorly directed, inner angles blunt and not projected; imaginary line tangent to posterolateral angles reaching distal margin of valvifers 9 ; inner margin not projected posteriorly; excavation V-shaped. Valvulae 8 barely exposed. Apices of laterotergites 8 slightly above level of apices of abdominal segment VII. Laterotergites 9 passing band connecting laterotergites 8 ; apices slightly above imaginary line tangent to apices of abdominal segment VII.

Measurements $(\mathrm{n}=9$; mm). Total length 17.1-19.2; head length 1.6-1.9; head width 3.5-4.0; pronotum width 11.4-12.6; abdomen width 9.0-10.0; length of antennomeres: I - 0.9-1.0; II - 1.8-2.0; III - 1.5; IV - 4.3-4.4; V - 4.9; scutellum length 8.1-8.9; scutellum width 5.9-6.8; pronotum length 3.2-3.7.

Differential diagnosis. For the males, see differential diagnosis of $H$. amyoti sp. nov. This species resembles $H$. belenensis sp. nov., $H$. favachae sp. nov. and $H$. servillei sp. nov. due to posterior margin of valvifers 8 concave or slanting, and never reaching posterior margin of valvifers 9. But $H$. aspilogaster sp. nov. can be separated by inner angle of posterior margin blunt, not dentiform like in the other species and by central excavation V-and not U-shaped like in the other species. The species $H$. belenensis sp. nov. has the apices of abdominal segment VII clearly
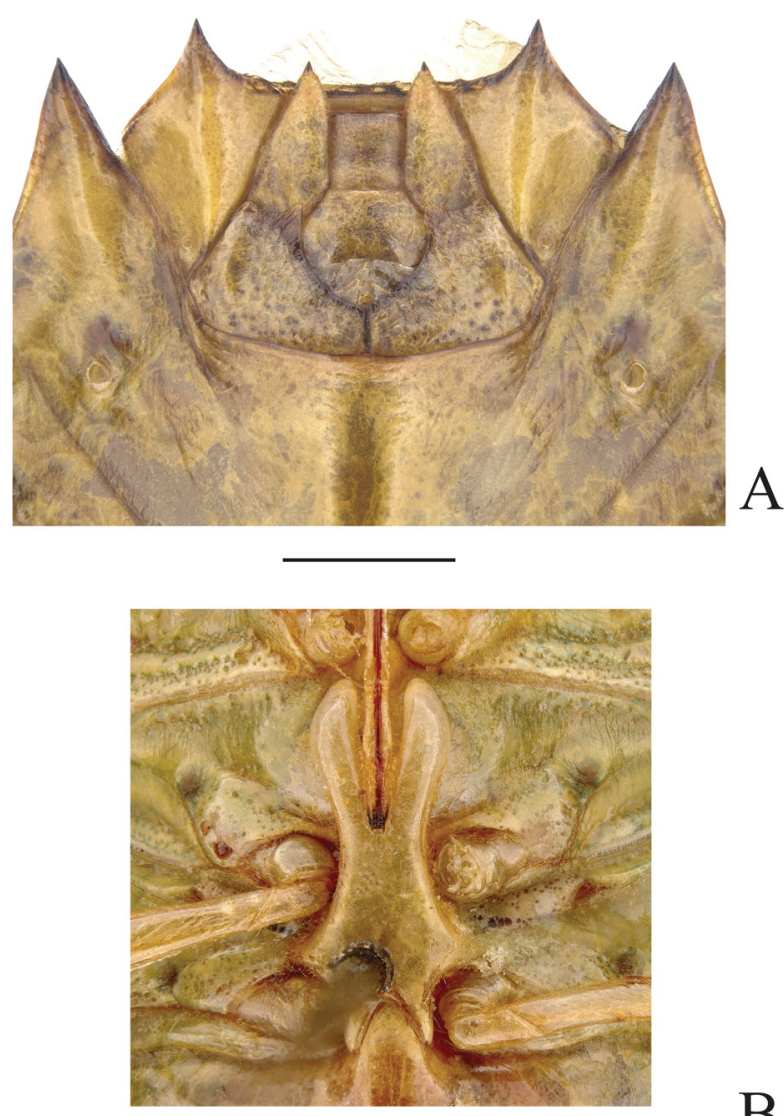

Figs 8A-B. Hypoxys belenensis sp. nov. A-genital plates; B - metasternal process. Scale bars $=1 \mathrm{~mm}$. below the level of the apices of laterotergites 8 and almost level with the apices of laterotergites 9 , whereas $H$. aspilogaster sp. nov., H. favachae sp. nov. and $H$. servillei $\mathrm{sp}$. nov. have the apices of abdominal segment VII almost level with the apices of laterotergites 8 and clearly above the level of laterotergites 9. Additionally, H. favachae sp. nov. differs from $H$. servillei $\mathrm{sp}$. nov. in the distal spine of laterotergites 8 a little bit narrower at base; and margin of valvifers 8 dark.

Etymology. Named for the absence of contrasting black spots on ventral side of the body (Gr. aspilos, spotless).

Distribution (Fig. 21A). Brazil: Minas Gerais, Espírito Santo and Rio de Janeiro.

\section{Hypoxys balteatus (Walker, 1868)}

Edessa balteata Walker, 1868: 436 (original description). Edessa balteata: KIRKALDY (1909): 154 (catalog); NunEs et al. (2020): 438 (diagnosis, distribution).

Diagnosis. See NunEs et al. (2020).

Differential diagnosis. Hypoxys balteatus resembles $H$. breddini sp. nov. and $H$. santarensis sp. nov. with all three presenting posterior margin of valvifers 8 slightly projected posteriorly, with the tangent line at distal margins of valvifers 8 not reaching middle of valvifers 9 . The species $H$. balteatus and H. santarensis sp. nov. can be separated from $H$. breddini sp. nov. by distal margin of valvifers 8 without small tooth-like projections (toothed in $H$. breddini sp. nov.). Hypoxys balteatus differs from $H$. santarensis
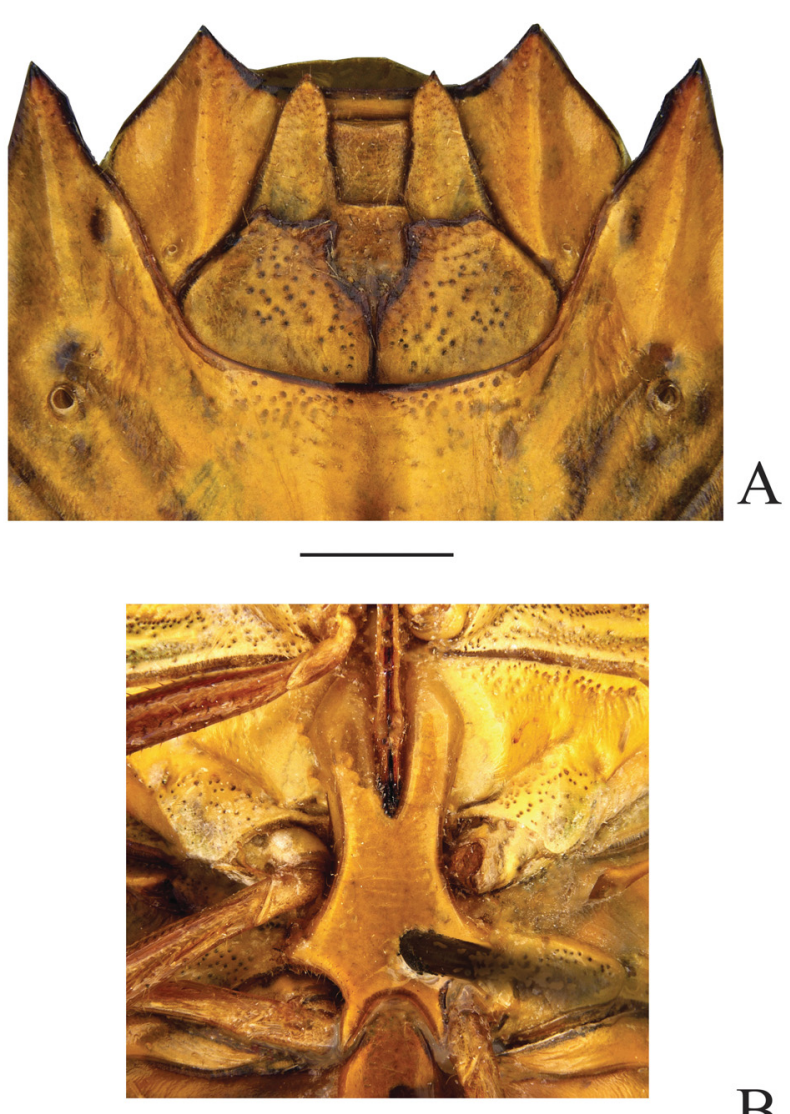

B

Figs 9A-B. Hypoxys bergrothi sp. nov. A - genital plates; B - metasternal process. Scale bars $=1 \mathrm{~mm}$. 
sp. nov. in rounded distal margins of valvifers 8 (straighter in $H$. santarensis sp. nov.); as a consequence, valvulae 8 are almost completely covered in $H$. balteatus and widely exposed in $H$. santarensis sp. nov. Excavation of valvifers 8 is much bigger in $H$. santarensis sp. nov. than in H. balteatus. Also, a closer look at the genital plates shows that in H. balteatus laterotergites 8 are almost level with apices of the abdominal segment VII (clearly surpassing them in H. santarensis sp. nov.); also apices of laterotergites 9 just surpass the band connecting laterotergites 8 in $H$. balteatus (clearly surpassing the band in $H$. santarensis $\mathrm{sp}$. nov.). Other difference can be found in the humeral angles of the three species; $H$. balteatus has the angle developed and curved backwards, $H$. breddini sp. nov. has the angle developed and straight, and $H$. balteatus shows less developed straight angle.

Distribution. Brazil: Pará (WALKer 1868, Nunes et al. 2020).

\section{Hypoxys belenensis sp. nov. (Figs 1E-F, 8A-B, 21B)}

Material examined. Holotype: + , BRAZIL: PARÁ: Belém/17.vi.1954 / W. Forster leg. (ZSMC).

Diagnosis. Antennae brown. Antennomere II longer than III. Pronotum with smoky stripe not reaching posterior margin. Thoracic and abdominal pleurites and sternites with black spots (Fig. 1F). Anterior excavation of metasternal process harboring fourth, third and part of second rostral segment (Fig. 8B). Female genitalia. Genital plates (Fig. 8A). Valvifers 8 posterior margin with posterolateral angles blunt, inner angles dentiform; both angles posteriorly directed to base of laterotergites 8 ; imaginary line tangent to posterolateral angles not reaching distal margin of valvifers 9; excavation widely U-shaped. Valvulae 8 well visible. Apices of laterotergites 8 clearly above level of apices of abdominal segment VII. Laterotergites 9 surpassing band connecting laterotergites 8 ; apices at level of imaginary line tangent to apices of abdominal segment VII. Male genitalia. Unknown.

Measurements $(\mathrm{n}=1$; mm). Total length 14.1; head length 1.5 ; head width 3.1 ; pronotum width 8.7 ; abdomen width 7.1; length of antennomeres: I - 0.7; II - 1.5; III 1.2; IV - 3.3; V-missing; scutellum length 6.5 ; scutellum width 4.8 ; pronotum length 2.7 .

Differential diagnosis. See differential diagnosis of $H$. aspilogaster sp. nov.

Etymology. Named after the type locality of the species; adjective.

Distribution (Fig. 21B). Brazil: Pará.

\section{Hypoxys bergrothi sp. nov.} (Figs 2A-B, 9A-B, 21B)

Material examined. Holotype: FRENCH GUIANA: SAINT-ELIE: Inselberg Haute-Koursibo / Savane-roche / 26.x.2013 (MNHN). PARATYPE: VENEZUELA: AMazonas: ${ }_{+}$, Mouth Cunucuna / 6.vi.1950 / J. Maldonado Capriles col. (USNM).

Diagnosis. Antennae brown. Antennomere II longer than III. Pronotum with smoky stripe not reaching posterior mar- gin. Thoracic and abdominal pleurites and sternites with black spots (Fig. 2B). Anterior excavation of metasternal process harboring fourth, third and less than half of second rostral segment (Fig. 9B). Female genitalia. Genital plates (Fig. 9A). Valvifers 8 posterior margin with posterolateral angles blunt, inner angles short, rounded and directed to valvifers 9; imaginary line tangent to posterolateral angle almost reaching distal margin of valvifers 9; inner margin not projected posteriorly; excavation U-shaped. Valvulae 8 visible. Apices of laterotergites 8 clearly above level of apices of abdominal segment VII. Laterotergites 9 surpassing band connecting laterotergites 8; apices clearly below imaginary line tangent to apices of abdominal segment VII. Male genitalia. Unknown.

Measurements $(\mathrm{n}=2$; holotype first; $\mathrm{mm})$. Total length 17.2 / 18.3; head length 1.7 /2.0; head width 3.5 / 3.5 (no span); pronotum width 10.3 / 11.5; abdomen width 8.7 / 10.0; length of antennomeres: I - 0.9 / 1.0; II - 1.6 / 1.6; III - 1.5 / 1.5 (no span); IV - 4.2 / 4.4; V - missing; scutellum length 7.9 / 7.9 (no span); scutellum width 5.7 / 6.5; pronotum length 3.4 / 3.5 .

Differential diagnosis. Hypoxys bergrothi sp. nov. is the only species that presents valvifers 8 overlapping lateral margin of valvifers 9 , leaving the excavation narrow, as narrow as segment $\mathrm{X}$. The other species all have the excavation wider than segment $\mathrm{X}$.

Etymology. Named after Ernst Evald Bergroth (18571925), the Finnish entomologist that made significant contributions to the study of Pentatomidae.

Distribution (Fig. 21B). Venezuela: Amazonas; French Guiana: Saint-Elie.

\section{Hypoxys breddini sp. nov. (Figs 2C-D, 10A-F, 21A)}

Material examined. Holotype: BOLIVIA: SAN Carlos: Mapiri (IRSB). Paratypes: BOLIVIA: SANTA CruZ: $\odot$, Potrerillos del Guendá / 5-20.xi.2004 / B. K. Dozier // $7^{\circ} 40.20$ S -063 $3^{\circ} .27 .44$ W (JEE). SAN CARLos: + , Sarampiuni / 8.ix.1950 / W. Forster leg. (ZSMC); + , no data (UFRGS).

Diagnosis. Antennae reddish (Fig. 2C). Antennomere III longer than II. Pronotum with smoky stripe reaching posterior margin. Thoracic and abdominal pleurites and sternites with black spots (Fig. 2D). Anterior excavation of metasternal process harboring fourth and almost whole third rostral segment (Fig. 10F). Male genitalia. Pygophore (Figs 10A-D). Posterolateral angles developed, bent inwards (Fig. 10A). Superior process of genital cup bilobate, short and close to proctiger; inner and outer ends projected ventrally (Figs 10C,D). Paramere with two lobes; anterior lobe developed, triangular and directed to base of proctiger; lateral lobe large and rounded (Figs 10C,D). Proctiger with scattered setae on lateral excavation; posterior face subtriangular (Figs 10A-C). Ventral rim with expansions acuminate, ventrolateral side gently impressed, dorsal side with brown spot on margin; barely surpassing level of posterolateral angles (Fig. 10B). Female genitalia. Genital plates (Fig. 10E). Valvifers 8 posterior margin with posterolateral angles dentiform and short, inner angles dentiform, reaching valvifers 9 ; imaginary line tangent to 

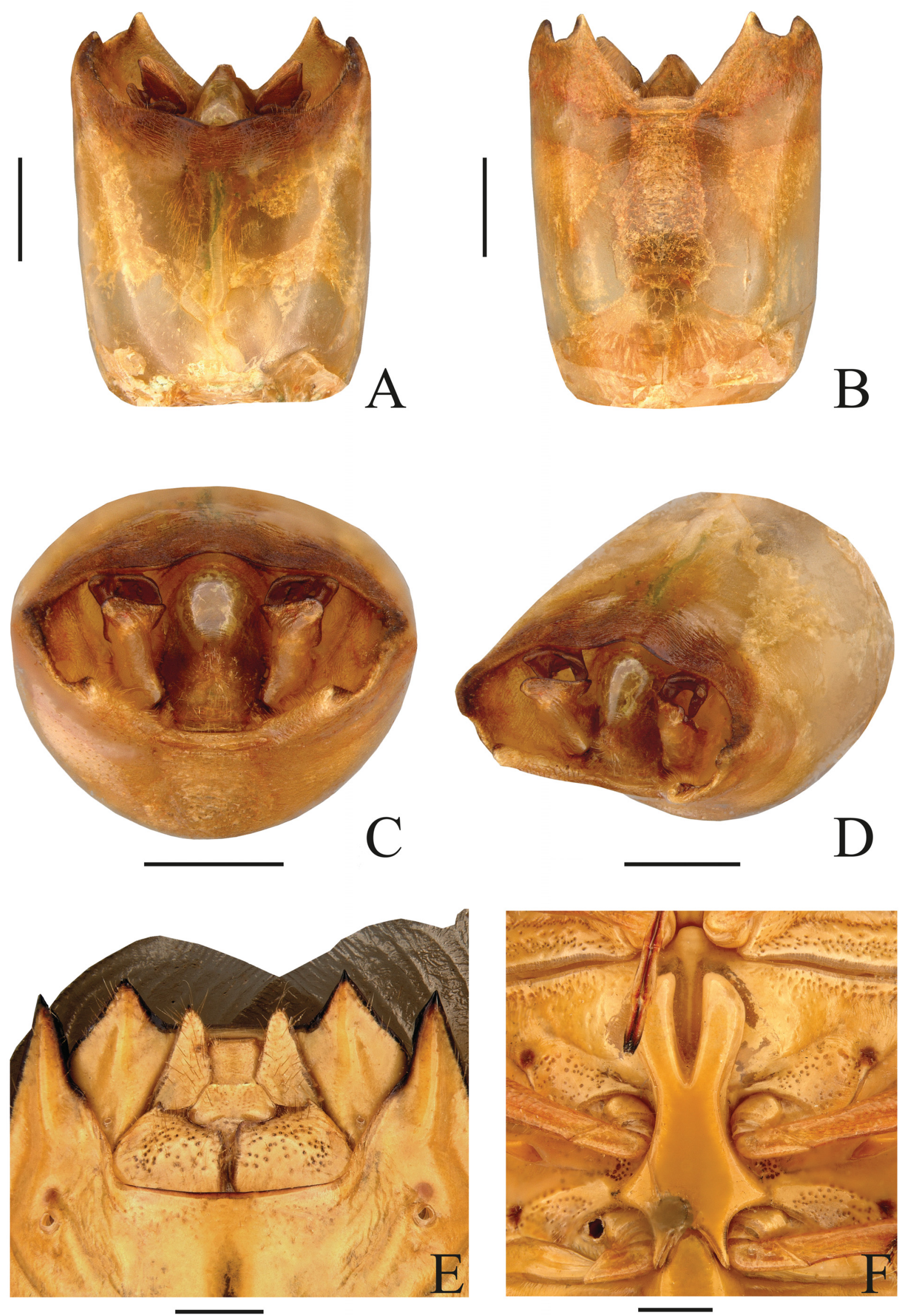

Figs 10A-F. Hypoxys breddini sp. nov. A-D - pygophore in dorsal, ventral, posterior and posterolateral view, respectively; E - genital plates; F - metasternal process. Scale bars $=1 \mathrm{~mm}$. 
posterolateral angles not reaching medial line of valvifers 9; excavation widely U-shaped. Valvulae 8 visible. Apices of laterotergites 8 clearly above level of apices of abdominal segment VII. Laterotergites 9 clearly surpassing band connecting laterotergites 8 ; apices clearly below imaginary line tangent to apices of abdominal segment VII.

Measurements $(\mathrm{n}=4$; mm). Total length 17.0-18.2; head length 1.6-1.8; head width 3.2-3.5; pronotum width 10.2-11.9; abdomen width 8.2-9.0; length of antennomeres: I - 0.8-0.9; II - 1.4-1.6; III - 1.5-1.8; IV - 1.8-3.5; V 3.3-4.0; scutellum length 7.4-8.4; scutellum width 5.7-6.0; pronotum length 3.1-3.5.

Differential diagnosis. See differential diagnosis of $H$. balteatus.

Etymology. Named after Gustav Breddin (1864-1909), the German entomologist that made the most important contribution to the knowledge of Hypoxys in the early $20^{\text {th }}$ century. Distribution (Fig. 21A). Bolivia: Santa Cruz and San Carlos.

\section{Hypoxys caquetensis sp. nov. (Figs 2E-F, 11A-B, 21A)}

Material examined. Holotype: + , COLOMBIA: CAQuetá: Rio Orteguaza / 14-18.i.1969 / Duckorth and Dietz (USNM).

Diagnosis. Antennae brown. Antennomere II longer than III. Pronotum with smoky stripe reaching posterior margin. Thoracic and abdominal pleurites and sternites with
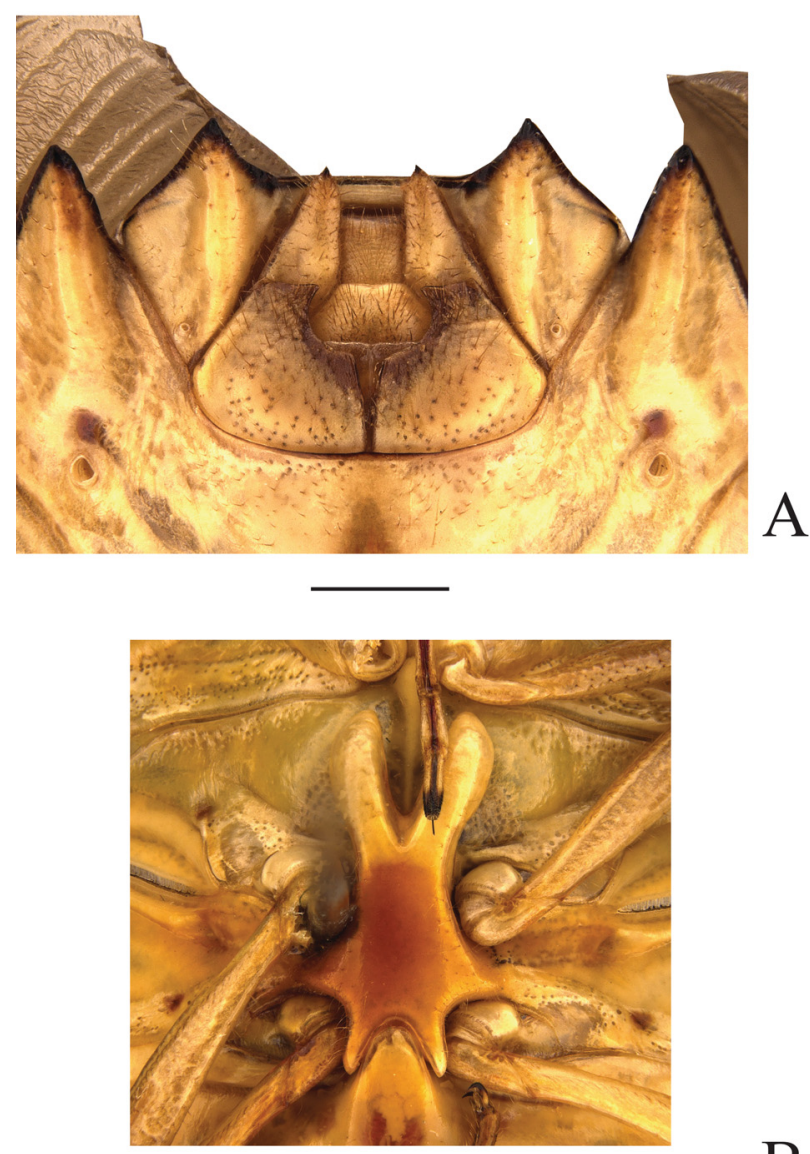

Figs $11 \mathrm{~A}-\mathrm{B}$. Hypoxys caquetensis sp. nov. A - genital plates; B - metasternal process. Scale bars $=1 \mathrm{~mm}$. black spots (Fig. 2F). Anterior excavation of metasternal process harboring fourth and whole third rostral segment (Fig. 11B). Female genitalia. Genital plates (Fig. 11A). Valvifers 8 posterior margin with posterolateral angles barely developed; inner angles dentiform directed to valvifers 9; imaginary line tangent to posterolateral angles reaching distal margin of valvifers 9; excavation in open U-shape. Valvulae 8 visible. Apices of laterotergites 8 clearly above level of apices of abdominal segment VII. Laterotergites 9 slightly surpassing band connecting laterotergites 8 ; apices clearly below imaginary line tangent to apices of abdominal segment VII. Male genitalia. Unknown.

Measurements $(\mathrm{n}=1$; mm). Total length 18.2; head length 1.6; head width 3.4 ; pronotum width 11.6; abdomen width 9.5; length of antennomeres: I - 0.7; II - 1.9; III - 1.4; IV: missing; V: missing; scutellum length 8.4; scutellum width 6.3; pronotum length 3.4 .

Differential diagnosis. The species $H$. caquetensis sp. nov. presents common characters shared by most species of the group but it differs from the others in the posterior margin of valvifers 8 almost straight and level with the distal margin of valvifers 9 .

Etymology. Named after the type locality of the species; adjective.

Distribution (Fig. 21A). Colombia: Caquetá.

\section{Hypoxys favachae sp. nov. (Figs 3A-B, 12A-F, 21A)}

Material examined. Holotype: đo, BRAZIL: PARÁ: Óbidos, Amazonas [river] / 6.vii.1930 / via. H. Rollé (USNM). PARATYPES: SURINAME: SIPALIWINI: + , Kaysergebergte / 25.xi-14.xii. 1960 / Sagiman Moentari (FMNH); BRAZIL: AMAPá: + , Rio Amapari / J. L. Lane col. // 26.vi.1959 / Anicohí (MZUSP).

Diagnosis. Antennae brown. Antennomere II longer than III. Pronotum with smoky stripe reaching posterior margin. Thoracic and abdominal pleurites and sternites with black spots (Fig. 3B). Anterior excavation of metasternal process harboring fourth and third rostral segment (Fig. 12F). Male genitalia. Pygophore (Figs 12A-D). Posterolateral angles slightly developed, straight and rounded (Fig. 12A). Superior process of genital cup large, robust, strongly convex, ventral part thick; inner dorsal angle produced in digitiform long process (Figs 12A,C,D); parallel to dorsal rim and almost reaching apex of posterolateral angle (Figs 12C,D). Paramere with two lobes; anterior lobe narrow, long and triangular, and directed to dorsal rim; lateral lobe short and rounded (Figs 12C,D). Proctiger with scattered setae on lateral excavation, slightly tumid dorsoposteriorly; posterior face triangular (Figs 12C,D). Ventral rim with expansions large, distally rounded, ventrolateral side broadly excavated, dorsal side with brown spot; clearly surpassing level of posterolateral angles (Fig. 12B). Female genitalia. Genital plates (Fig. 12E). Valvifers 8 with posterior and inner margins dark; posterior margin slanting with posterolateral angles little developed, dentiform and posteriorly directed, inner angles acute and slightly curved, directed to valvifers 9; imaginary line tangent to posterolateral angles not reaching distal margin of valvifers 9; excavation in open U-shape. Valvulae 8 visible. Apices of laterotergites 

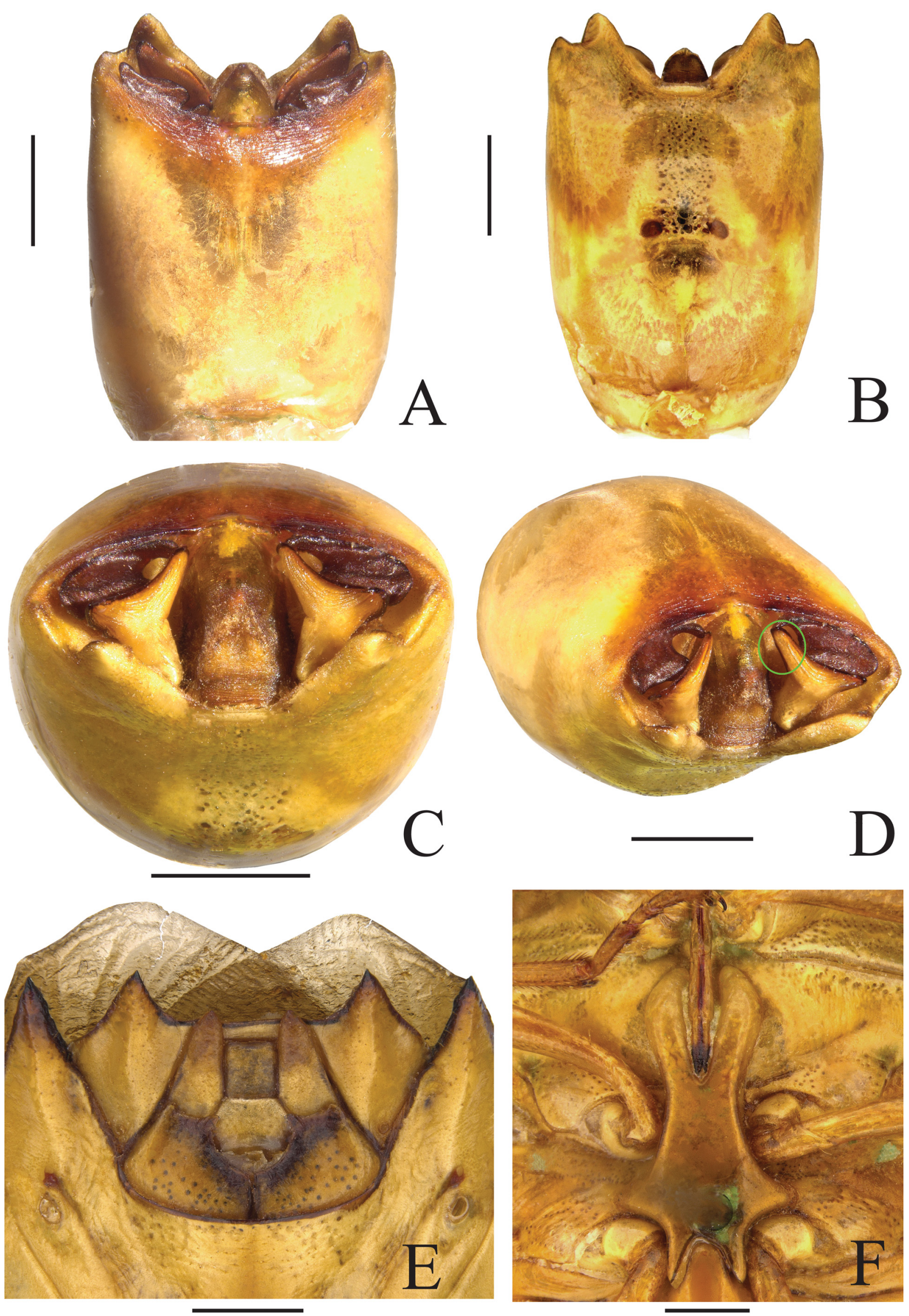

Figs 12A-F. Hypoxys favachae sp. nov. A-D - pygophore in dorsal, ventral, posterior and posterolateral view, respectively; E - genital plates; F - metasternal process. Green circle in Fig. D indicates the anterior lobe of paramere. Scale bars $=1 \mathrm{~mm}$. 
8 slightly above level of apices of abdominal segment VII. Laterotergites 9 slightly surpassing band connecting laterotergites 8; apices clearly below imaginary line tangent to apices of abdominal segment VII.

Measurements $(\mathrm{n}=3$; mm). Total length 15.8-17.2; head length $1.7-1.8$; head width $3.3-3.7$; pronotum width 9.4-10.8; abdomen width 7.7-8.8; length of antennomeres: I - 0.7-1.0; II - 1.2-1.8; III - 1.0-1.2; IV - 3.8-4.2; V-4.6; scutellum length 7.1-8.0; scutellum width 5.3-5.8; pronotum length 3.0-3.3.

Differential diagnosis. See differential diagnosis of the species $H$. aspilogaster sp. nov. for the female genitalia. As for the males, $H$. favachae sp. nov. resembles $H$. gaucho sp. nov. in presenting the superior process of genital cup large, robust, with ventral margin thick, and the inner dorsal angle produced in a digitiform process. But $H$. favachae sp. nov. differs from $H$. gaucho sp. nov. in the presence of a crown of dense setae on proctiger; the shape of the posterior face of proctiger; and the shape of the expansions of ventral rim. Etymology. Named after the first author's mother - Sileide Favacho.

Distribution (Fig. 21A). Suriname: Sipaliwini; Brazil: Amapá and Pará.

Remarks. The label of the holotype mentions "Amazonas" after Óbidos; we assume that this name refers to the river Amazonas not the State of Amazonas.

\section{Hypoxys gaucho sp. nov. \\ (Figs 3C-D, 13A-E, 21B)}

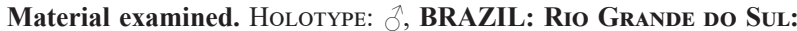
Derrubadas / 19.iv.2004 / Bernardes JLC (MZUSP).

Diagnosis. Antennae brown. Antennomere II longer than III. Pronotum with smoky stripe reaching posterior margin. Thoracic and abdominal pleurites and sternites with black spots (Fig. 3D). Anterior excavation of metasternal process harboring fourth and almost whole third rostral segment (Fig. 13E). Male genitalia. Pygophore (Figs 13A-D). Posterolateral angles developed, bent inwards, acuminate (Fig. 13A). Superior process of genital cup large, concave, parallel to dorsal rim, and almost reaching posterolateral angle, ventral margin thick and carinate, inner part medially notched, inner dorsal angle produced in long digitiform process (Figs 13C,D). Paramere with two lobes; anterior lobe square, large, and directed to base of proctiger; lateral lobe rounded (Figs 13C,D). Proctiger with dense crown of long setae on lateral excavations; posterior face subpentagonal and short (Figs 13C,D). Ventral rim with expansions long, acuminate, ventrolateral side broadly excavated and medially furrowed, dorsal side with light brown spot; surpassing level of posterolateral angles (Fig. 13B). Female genitalia. Unknown.

Measurements $(\mathrm{n}=1$; mm). Total length 15.0; head length 1.6 ; head width 3.2 ; pronotum width 9.4 ; abdomen width 7.5 ; length of antennomeres: I - 0.8 ; II - 1.7; III - 1.1; IV: missing; V: missing; scutellum length 6.7; scutellum width 5.4; pronotum length 2.7 .

Differential diagnosis. See differential diagnosis of $H$. favachae sp. nov. Additionally, H. gaucho sp. nov. shares with $H$. aspilogaster sp. nov. the expansions of ventral rim long and narrow but both species can be separated by the shape of the superior process of genital cup and the posterior face of proctiger.

Etymology. Named after the people born in Rio Grande do Sul State, Brazil. The name Gaucho is also used for the "cowboys" that traditionally inhabit the prairies (Pampa Biome) in Brazil (Rio Grande do Sul), Uruguay and Argentina. Noun in apposition.

Distribution (Fig. 21B). Brazil: Rio Grande do Sul.

\section{Hypoxys hyalinofasciatus sp. nov. (Figs 3E-F, 14A-E, 21B)}

Material examined. Holotype: ECUADOR: Sucumbíos: Rivers Napo-Aguarico / 20.x.1942 / Rarijsterborgh col. (USNM).

Diagnosis. Antennae reddish (Fig. 3E). Antennomere II longer than III. Pronotum with smoky stripe reaching posterior margin. Thoracic and abdominal pleurites and sternites with black spots (Fig. 3F). Anterior excavation of metasternal process harboring fourth and almost whole third rostral segment (Fig. 14E). Male genitalia. Pygophore (Figs 14A-D). Posterolateral angles developed, bent inwards, acuminate (Fig 14A). Superior process of genital cup elongated, parallel to dorsal rim, and slightly concave; inner (proximal) part truncate and strongly curved, ventral angle with dentiform process; outer (distal) part tonguelike (Figs 14C,D). Paramere with two lobes; anterior lobe square, large, and directed to dorsal rim; lateral lobe rounded and large (Figs 14C,D). Proctiger with dense short setae on lateral excavation; posterior face triangular (Figs $14 C, D)$. Ventral rim with expansions acuminate, narrow, apices curved inwards, ventrolateral side furrowed, dorsal side with brown spot; level or just surpassing posterolateral angles in ventral view (Fig. 14B). Female genitalia. Unknown.

Measurements $(\mathrm{n}=1)$. Total length 16.3; head length 1.4; head width 3.3 ; pronotum width 10.9; abdomen width 8.9; length of antennomeres: I - 0.7; II - 1.9; III - 1.5; IV - 5.7; V: missing; scutellum length 8.0; scutellum width 6.3; pronotum length 3.0.

Differential diagnosis. The species $H$. hyalinofasciatus sp. nov. shares with $H$. venustus sp. nov. the ventral rim expansions directed inwards. The species $H$. hyalinofasciatus $\mathrm{sp}$. nov. shares with $H$. immaculatus sp. nov., $H$. nigroantennatus sp. nov., H. santarensis sp. nov., H. servillei sp. nov., and $H$. venustus sp. nov. the superior process of the genital cup anteriorly truncated with ventral angle developed in a short projection and posterior part tongue-like. However, $H$. hyalinofasciatus sp. nov., $H$. nigroantennatus sp. nov. and $H$. santarensis sp. nov. differ from the others in dorsal margin of the paramere concave (convex margin in H. immaculatus sp. nov., H. servillei sp. nov. and $H$. venustus sp. nov.). The species $H$. hyalinofasciatus sp. nov. can be separated from $H$. nigroantennatus sp. nov. by the black antennae of the latter and from $H$. santarensis sp. nov. by the shape of the paramere, expansions of ventral rim narrow, long and slightly curved, and posterior face of proctiger triangular. Etymology. Named for the dark translucent band on the posterior margin of the pronotum (Latin hyalinus = glassy + fasciatus $=$ striped); adjective.

Distribution (Fig. 21B). Ecuador: Sucumbíos. 

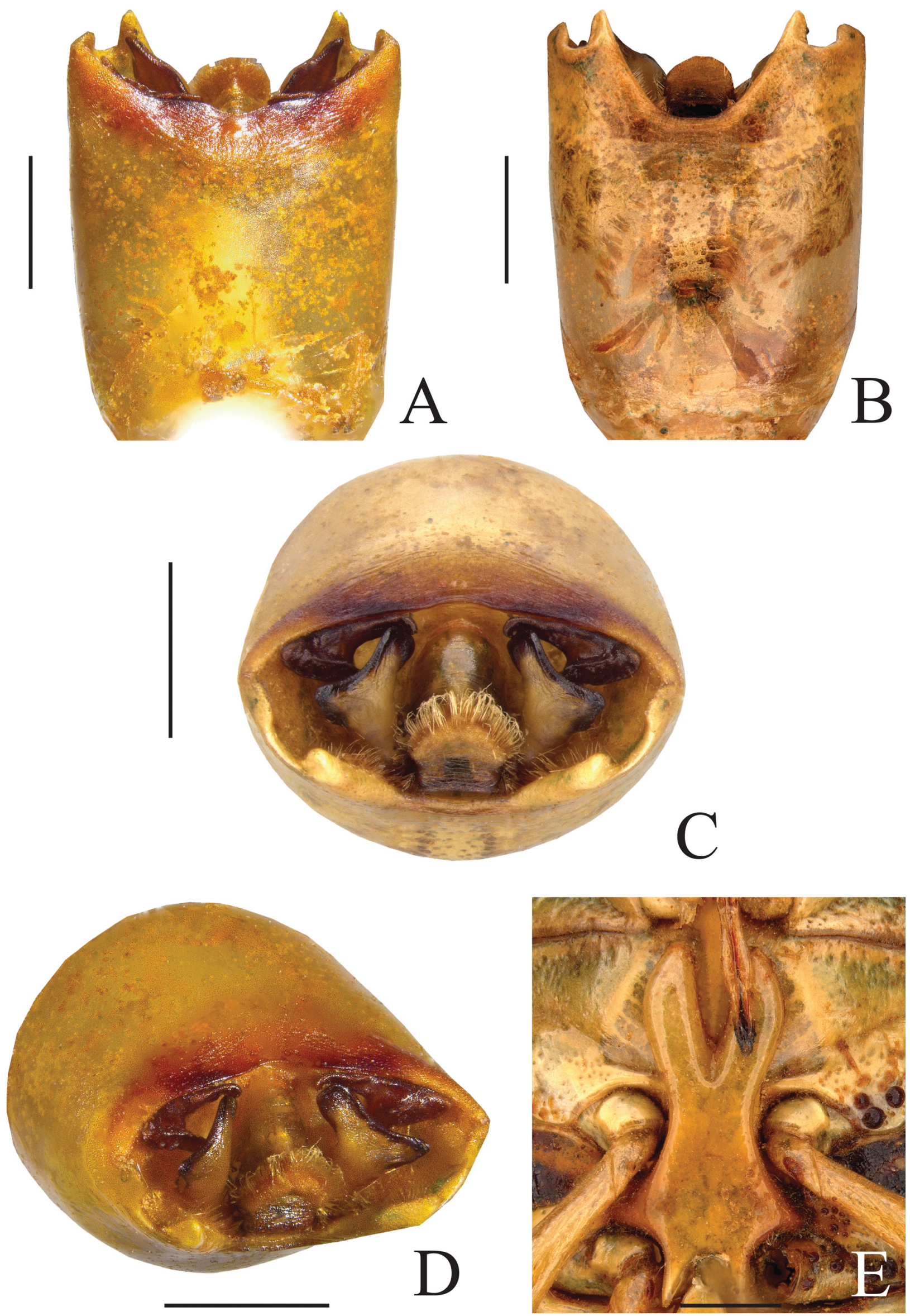

Figs 13A-E. Hypoxys gaucho sp. nov. A-D - pygophore in dorsal, ventral, posterior and posterolateral view, respectively; E - metasternal process. Scale bars $=1 \mathrm{~mm}$. 

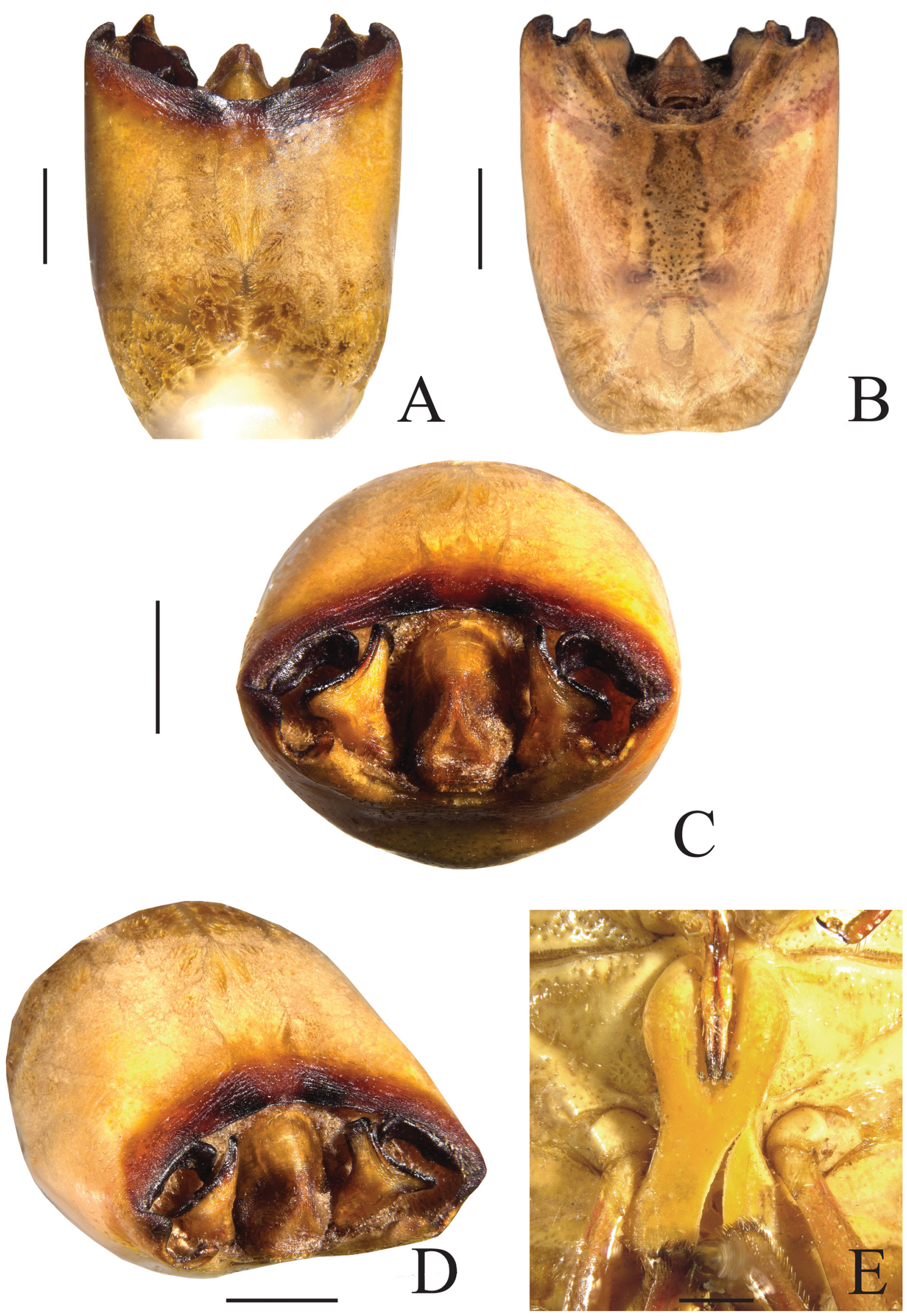

Figs 14A-E. Hypoxys hyalinofasciatus sp. nov. A-D - pygophore in dorsal, ventral, posterior and posterolateral view, respectively; E - metasternal process. Scale bars $=1 \mathrm{~mm}$. 


\section{Hypoxys immaculatus sp. nov. (Figs 4A-B, 15A-E, 21B)}

Material examined. Holotype: $\widehat{\jmath}$, BOLIVIA: BeNI: Las Juntas / xii.1913 / Steinbach, Coll. (USNM).

Diagnosis. Antennae reddish (Fig. 4A). Antennomere III longer than II. Pronotum with smoky stripe not reaching posterior margin. Thoracic and abdominal pleurites and sternites without black spots (Fig. 4B). Anterior excavation of metasternal process harboring fourth and almost whole third rostral segment (Fig. 15E). Male genitalia. Pygophore (Figs 15A-D). Posterolateral angles little developed, bent inwards (Fig. 15A). Superior process of genital cup thick, parallel to dorsal rim, elongated, almost reaching posterolateral angles; inner (proximal) part truncate and curved, ventral angle with dentiform process; outer (distal) part tongue-like (Figs 15A,C,D). Paramere with two lobes; anterior lobe triangular, and directed to base of proctiger; lateral and dorsal lobes rounded and short (Figs 15C,D). Proctiger with dorsal tufts of setae on lateral excavation and margin of posterior face; posterior face triangular (Figs $15 \mathrm{C}, \mathrm{D})$. Ventral rim with expansions triangular, distally rounded, ventrolateral side gently impressed, dorsal side without dark spot; clearly surpassing level of posterolateral angles (Fig. 15B). Female genitalia. Unknown.

Measurements $(\mathrm{n}=1 ; \mathrm{mm})$. Total length 15.8 ; head length 1.7; head width 3.2; pronotum width 11.0; abdomen width 8.1; length of antennomeres: I - 0.9; II - 1.3; III - 1.7; IV - 3.9; V - 4.0; scutellum length 7.4; scutellum width 5.6; pronotum length 3.2 .

Differential diagnosis. Hypoxys immaculatus sp. nov. and H. aspilogaster sp. nov. are the only species of the group without dark spots on ventral surface, but the structure of the superior process of genital cup groups together $H$. immaculatus sp. nov., H. hyalinofasciatus sp. nov., $H$. nigroantennatus sp. nov., $H$. santarensis sp. nov., $H$. servillei $\mathrm{sp}$. nov., and $H$. venustus sp. nov. See differential diagnosis of $H$. hyalinofasciatus sp. nov. for more details. Etymology. Named for the absence of black marks on ventral side of the body (Latin immaculatus $=$ spotless); adjective.

Distribution (Fig. 21B). Bolivia: Beni.

\section{Hypoxys nigroantennatus sp. nov. (Figs 4C-D, 16A-F, 21B)}

Material examined. HoLOTYPE: FRENCH GUIANA: Roura / i.1986 / G. Tavakilian (MNHN). PARATYPES: FRENCH GUIANA: $\odot, 1984$ / G. Tavakilian Rec. (MNHN); + , 22.vii.1984 / G. Tavakilian Rec. (MNHN); + , 5-7.vi.2005 / J. E. Eger and M. T. Messenger col. // 04'32.214' N $052^{\circ} 07.420^{\prime} \mathrm{W} / /$ (JEE); + , 2.ii.1984 / G. Tavakilian Rec. (UFRGS).

Diagnosis. Antennae black (Figs 4C,D). Antennomere II longer than III. Apex of mandibular plates with black stripe (Figs 4C,D). Pronotum with smoky stripe reaching posterior margin. Thoracic and abdominal pleurites and sternites with black spots (Figs 16F, 4D). Anterior excavation of metasternal process harboring fourth, third and part of second rostral segment (Fig. 16F). Male genitalia. Pygophore (Figs 16A-D). Posterolateral angles developed, straight, acuminate (Fig. 16A). Superior process of genital cup parallel to dorsal rim, elongated, almost reaching posterolateral angles, concave medially; inner (proximal) part truncate, ventral angle with large dentiform process; outer (distal) part tongue-like and enlarged (Figs 16C,D). Paramere with two lobes; anterior lobe square, large, and directed to base of proctiger; lateral lobe large and rounded (Figs 16C,D). Proctiger with posterior face triangular (Figs 16C,D). Ventral rim with expansions developed, distally acuminate, ventrolateral side with broad striated excavation, dorsal side with light brown spot; clearly surpassing level of posterolateral angles (Figs 16B,C). Female genitalia. Genital plates (Fig. 16E). Valvifers 8 posterior margin with posterolateral angles dentiform and posteriorly directed, inner angle not visible; imaginary line tangent to posterolateral angles not reaching distal margin of valvifers 9; excavation V-shaped. Valvulae 8 visible. Apices of laterotergites 8 clearly above level of apices of abdominal segment VII. Laterotergites 9 surpassing band connecting laterotergites 8 ; apices slightly below imaginary line tangent to apices of abdominal segment VII.

Measurements $(\mathrm{n}=5$; mm). Total length 18.4-19.6; head length 1.8-2.3; head width 3.8-4.3; pronotum width 10.2-11.8; abdomen width 8.7-9.8; length of antennomeres: I - 1.0-1.2; II - 2.0-2.3; III - 1.3-1.5; IV - 4.7-7.5; $\mathrm{V}$ : missing; scutellum length 7.6-8.7; scutellum width 5.8-7.0; pronotum length 3.4-4.1.

Differential diagnosis. Hypoxys nigroantennatus sp. nov. differs from the other species of the H. balteatus species group because the antennae and margin of the mandibular plates are black; valvifers 8 excavation is also unique in the group. Also see differential diagnosis of $H$. hyalinofasciatus sp. nov. for more details.

Etymology. Named for the black coloration of the antennae (Latin niger = black, antennatus = bearing antennae); adjective.

Distribution (Fig. 21B). French Guiana: Roura.

Remark. All setae from proctiger were removed when cleaning the pygophore.

\section{Hypoxys santarensis sp. nov.} (Figs 4E-F, 17A-F, 21B)

Material examined. Holotype: BRAZIL: Pará: Santarém / 30.iv.1931 / C. H. Townsend (USNM). PARATYPE: BRAZIL: Pará: + , same data as holotype except: 17.vi.1931 (USNM).

Diagnosis. Antennae brown. Antennomere II longer than III. Pronotum with smoky stripe not reaching posterior margin. Thoracic and abdominal pleurites and sternites with black spots (Fig. 4F). Anterior excavation of metasternal process harboring fourth and almost half of third rostral segment (Fig. 17F). Male genitalia. Pygophore (Figs 17A-D). Dorsal rim with small lateral projection rounded close to posterolateral angles (Fig. 17A, arrow). Posterolateral angles developed, rounded, and straight (Fig. 17A). Superior process of genital cup parallel to dorsal rim, short, narrow, slightly concave medially; inner (proximal) part truncate, ventral angle with dentiform process; outer (distal) part tongue-like and enlarged, dorsal margin tumid (Figs 17C,D). Paramere with two lobes; both lobes long and rounded distally, resembling whale tail; anterior lobe directed to base of proctiger (Figs 17C,D). Proctiger with 

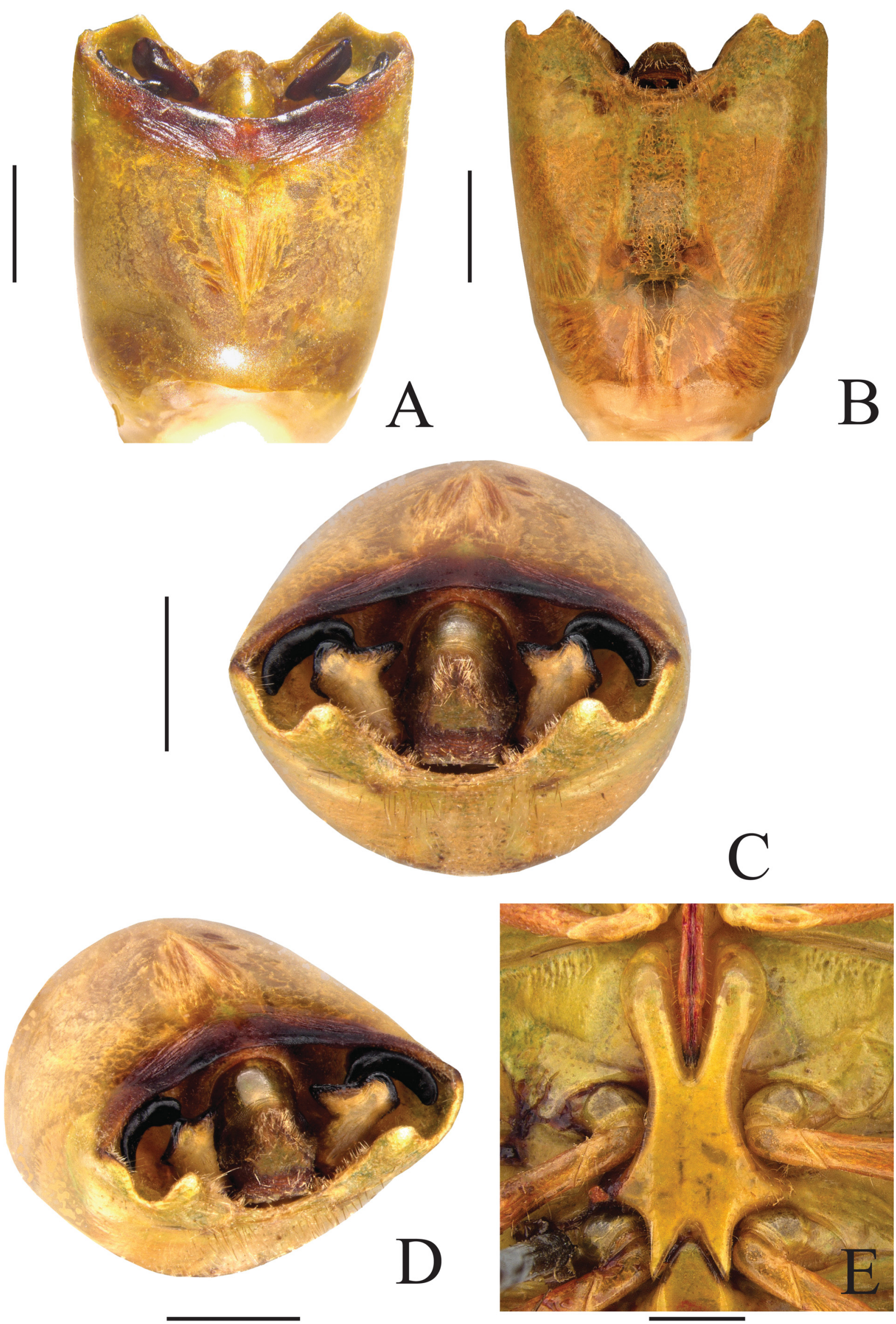

Figs 15A-E. Hypoxys immaculatus sp. nov. A-D - pygophore in dorsal, ventral, posterior and posterolateral view, respectively; E - metasternal process. Scale bars $=1 \mathrm{~mm}$. 

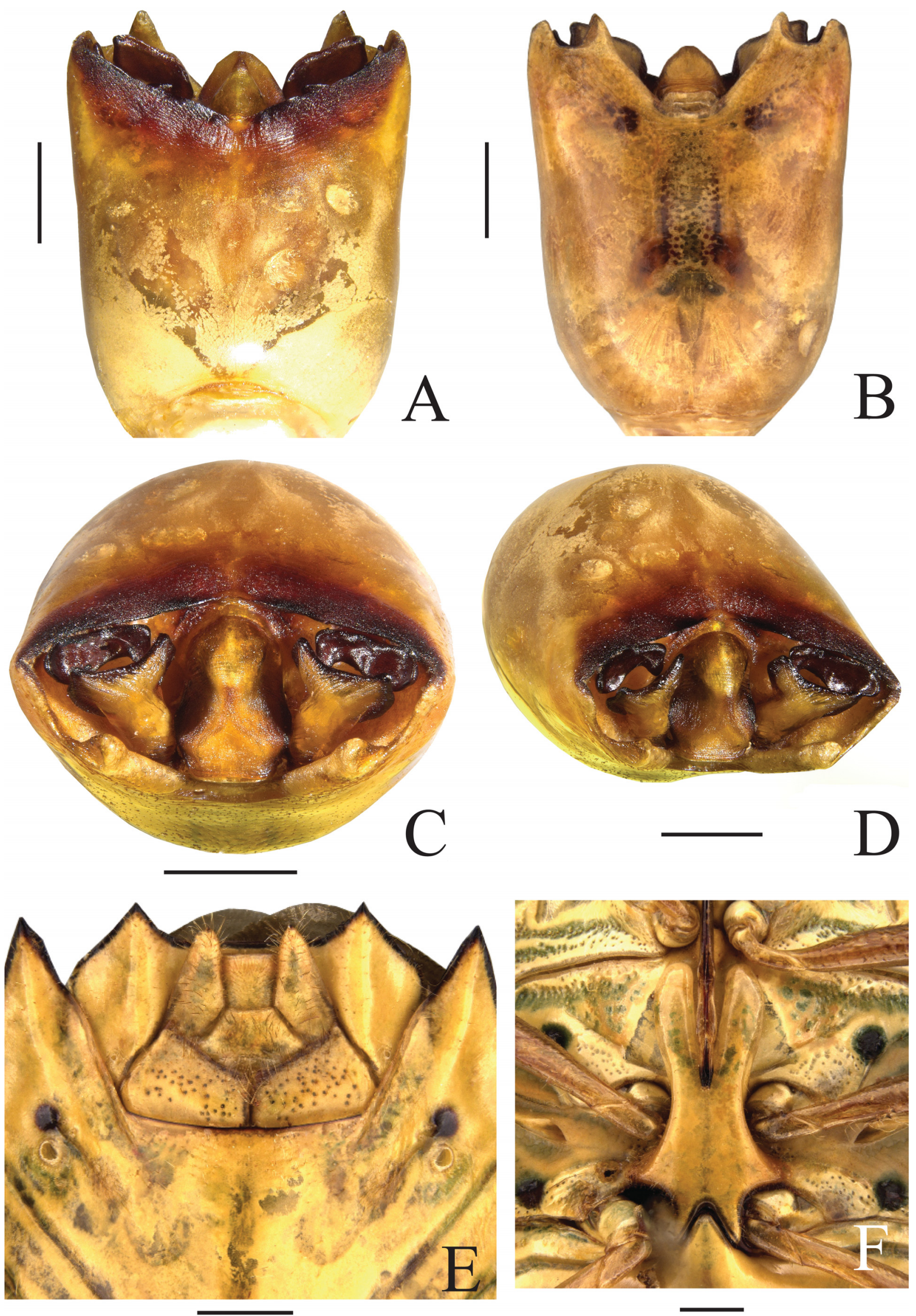

Figs 16A-F. Hypoxys nigroantennatus sp. nov. A-D - pygophore in dorsal, ventral, posterior and posterolateral view, respectively; E - genital plates; $\mathrm{F}-$ metasternal process. Scale bars $=1 \mathrm{~mm}$. 

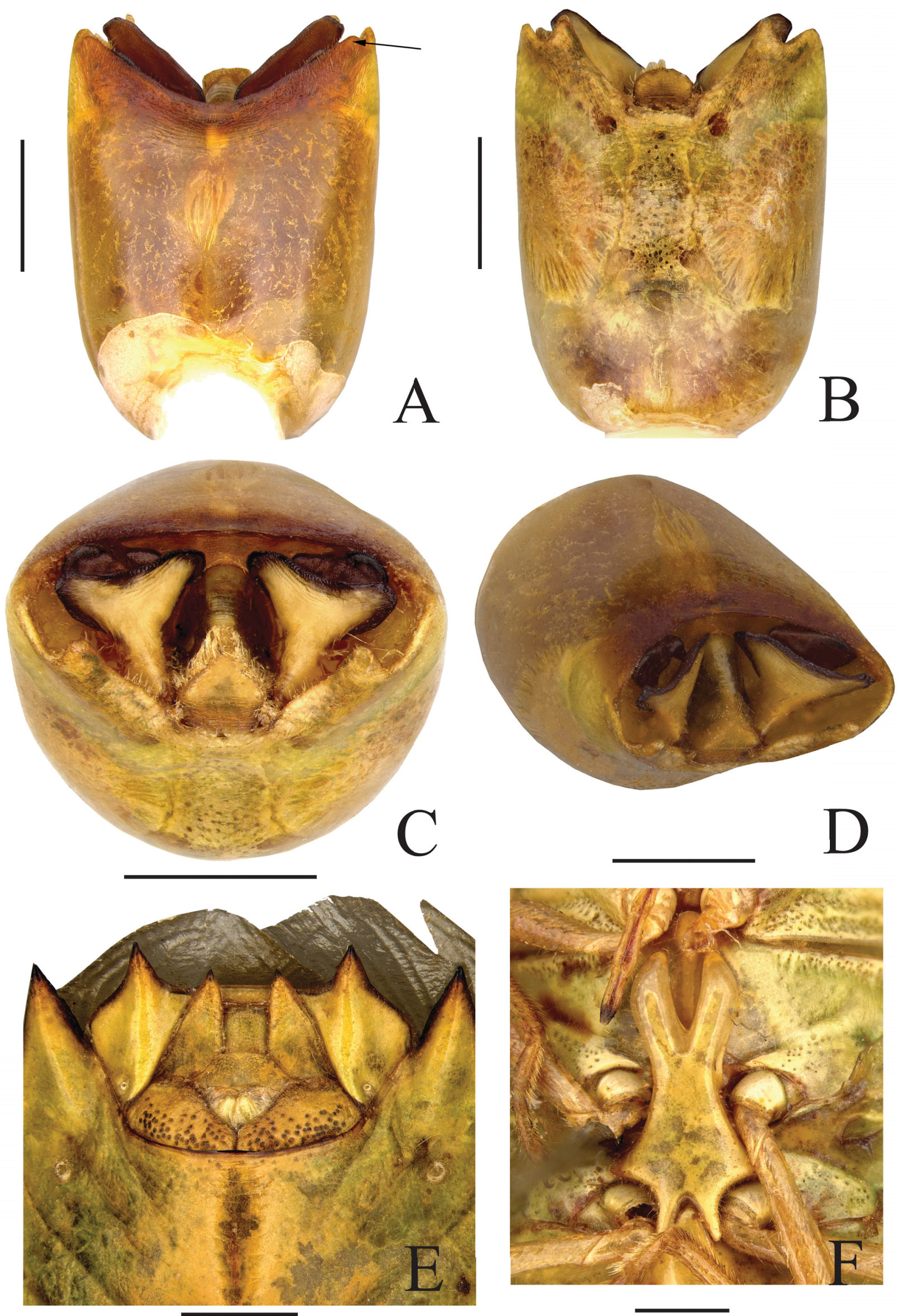

Figs 17A-F. Hypoxys santarensis sp. nov. A-D - pygophore in dorsal, ventral, posterior and posterolateral view, respectively; E - genital plates; F metasternal process. Arrow indicates the lateral projection of the dorsal rim. Scale bars $=1 \mathrm{~mm}$. 
tufts of long setae along lateral excavation; posterior face subpentagonal (Figs 17C,D). Ventral rim with expansions triangular, short, distally blunt, inner lateral face not excavated, dorsal side without dark spot; slightly surpassing level of posterolateral angles (Fig. 17B). Female genitalia. Genital plates (Fig. 17E). Valvifers 8 without dentiform angles, posterior margin almost straight, barely slanting; imaginary line tangent to posterior margin not reaching medial line of valvifers 9; excavation V-shaped. Valvulae 8 exposed. Apices of laterotergites 8 above level of apices of abdominal segment VII. Laterotergites 9 surpassing band connecting laterotergites 8; apices almost reaching imaginary line tangent to apices of abdominal segment VII.

Measurements $(\mathrm{n}=2$; holotype first; $\mathrm{mm})$. Total length 12.9 / 14.5; head length 1.3 / 1.6; head width 2.9 / 3.0; pronotum width 8.0 / 8.4; abdomen width 6.5 / 7.2; length of antennomeres: I - 0.8 / 0.9; II - 1.2 / 1.5; III - 1.1 / 1.3; IV - 3.0 / 3.3; V - 3.5 / 3.6; scutellum length 5.7 / 6.3; scutellum width 4.4 / 4.7; pronotum length 2.5 / 2.8 .

Differential diagnosis. Considering only the female genitalia, $H$. santarensis sp. nov. is similar to $H$. balteatus and $H$. breddini sp. nov.; see the differential diagnosis of $H$. balteatus. Considering only the male genitalia, $H$. santarensis sp. nov. is part of a large group of six species; see differential diagnosis of $H$. hyalinofasciatus sp. nov.. Etymology. Named after the type locality of the species; adjective.

Distribution (Fig. 21B). Brazil: Pará.

\section{Hypoxys servillei sp. nov. (Figs 5A-B, 18A-F, 21B)}

Material examined. HоLотYPE: đ, BRAZIL: GoIÁs: Jataí / 1904 / H. Donckier (MNHN). ParatyPe: BRAZIL: Mato Grosso: + , Chapada dos Guimarães / 6.ii.1961 / Jan Bechyné (MPEG); + , same place / 23.v.2011 / S. Klemp (UFMT); same data holotype: $\odot$ (MNHN).

Diagnosis. Antennae brown. Antennomere III longer than II. Pronotum with smoky stripe reaching posterior margin (Fig. 5A). Thoracic and abdominal pleurites and sternites with black spots (Fig. 5B). Anterior excavation of metasternal process harboring fourth and less than half of third rostral segment (Fig. 18F). Male genitalia. Pygophore (Figs 18A-D). Posterolateral angles developed, bent inwards, acuminate (Fig. 18A). Superior process of genital cup parallel to dorsal rim, long, almost reaching posterolateral angles, slightly concave medially; inner (proximal) part truncate, ventral angle with long digitiform process; outer (distal) part tongue-like and enlarged (Figs 18C,D). Paramere with two lobes; anterior lobe triangular, long, and directed to base of proctiger; lateral lobe short and rounded (Figs 18C,D). Proctiger with tufts of long setae along lateral excavation; posterior face bell-shaped (Figs 18C,D). Ventral rim with expansions developed, robust, distally rounded, ventrolateral side with broad striated excavation, dorsal side with brown spot; surpassing level of posterolateral angles (Fig. 18B). Female genitalia. Genital plates (Fig. 18E). Valvifers 8 posterior margin slightly concave, posterolateral angle dentiform and posteriorly directed, inner angle dentiform and projected to valvifers 9; imaginary line tangent to posterolateral angles almost reaching distal margin of valvifers 9; U-shaped excavation. Valvulae 8 visible. Apices of laterotergites 8 just passing level of apices of abdominal segment VII. Laterotergites 9 surpassing band connecting laterotergites 8; apices clearly below imaginary line tangent to apices of abdominal segment VII.

Measurements $(\mathrm{n}=4$; mm). Total length 16.2-18.6; head length 1.7-1.9; head width 3.1-3.2; pronotum width 10.6-11.2; abdomen width 7.8-8.5; length of antennomeres: I - 0.8-1.0; II - 1.1-1.5; III - 1.4-3.5; IV - 3.6; $\mathrm{V}$ - missing; scutellum length 7.3-7.5; scutellum width 5.3-5.5; pronotum length 3.1-4.8.

Differential diagnosis. For the female genitalia see differential diagnosis of $H$. aspilogaster sp. nov.; for male genitalia see differential diagnosis of $H$. hyalinofasciatus sp. nov.

Etymology. Named after Jean Guillaume Audinet-Serville (1775-1858), the great French entomologist and coauthor of 'Histoire naturelle des insectes Hémiptères' with C. J.-B. Amyot.

Distribution (Fig. 21B). Brazil: Mato Grosso and Goiás.

\section{Hypoxys stysi sp. nov. \\ (Figs 5C-D, 19A-F, 21A)}

Material examined. HoLOTYPE: $\widehat{\partial}$, SURINAME: CoRonIE: Suriname exp 1948-1949 / Coronieweg 216 / zandzitsen / 18.xii.1948 (RMNH). PARATYPES: SURINAME: SIPALIWINI: $\odot$, Grandam/15.vii.1965// Mees GF / E. quadridens F. (Hypoxys) // (RMNH). FRENCH GUIANA: CAYENnE: + , E. quadridens Fabr. (MNHN).

Diagnosis. Antennae brown. Antennomere II longer than III. Pronotum with smoky stripe reaching posterior margin. Thoracic and abdominal pleurites and sternites with black spots (Fig. 5D). Anterior excavation of metasternal process harboring fourth and almost whole third rostral segment (Fig. 19F). Male genitalia. Pygophore (Figs 19A-D). Dorsal rim with small round projections adjacent to posterolateral angle (Fig. 19A). Posterolateral angles developed, bent inwards, acuminate (Fig. 19A). Superior process of genital cup trilobate, curved, elongated, concave medially, parallel to dorsal rim and almost reaching apex of posterolateral angle; inner part bifid, forming two long digitiform lobes; outer part tongue-like (Figs 19C,D). Paramere with two lobes; anterior lobe square, developed and directed to dorsal rim; lateral lobe small and rounded (Figs 19C,D). Proctiger with crown of long, dense setae on lateral excavation; posterior face subpentagonal (Figs 19C,D). Ventral rim with expansions acuminate, large, ventrolateral side broadly excavated, dorsal side without brown spot; almost level with posterolateral angles (Figs 19B,C). Female genitalia. Genital plates (Fig. 19E). Valvifers 8 posterior margin with posterolateral angles dentiform and posteriorly directed, inner angle dentiform and projected to valvifers 9 ; imaginary line tangent to posterolateral angles not reaching distal margin of valvifers 9; inner margin slightly projected posteriorly, leaving bottom of excavation convex; excavation in U-shaped. Valvulae 8 not visible. Apices of laterotergites 8 clearly above level of apices of abdominal segment VII. Laterotergites 9 slightly surpassing band connecting laterotergites 8; 

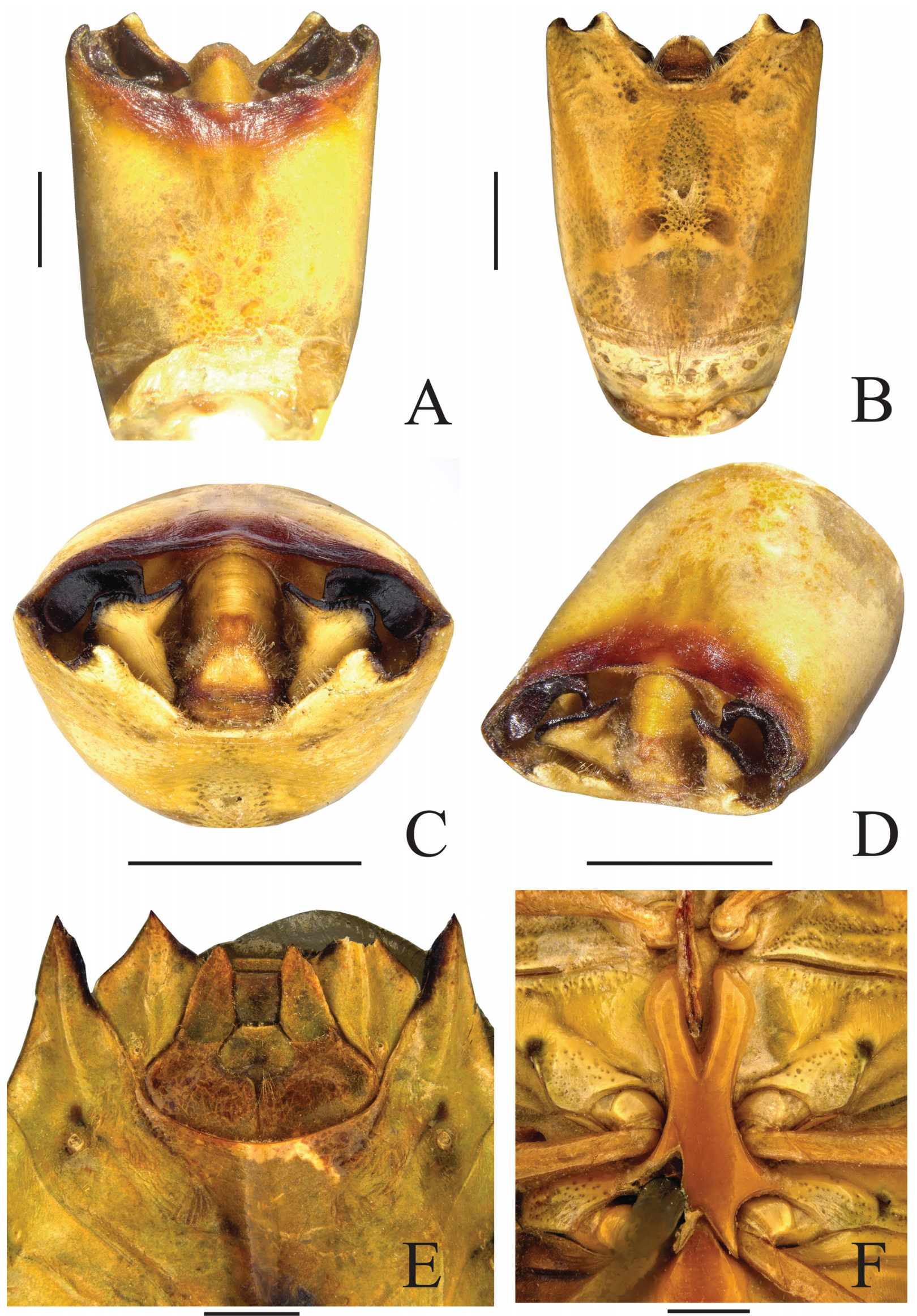

Figs 18A-F. Hypoxys servillei sp. nov. A-D - pygophore in dorsal, ventral, posterior and posterolateral view, respectively; E - genital plates; F - metasternal process. Scale bars $=1 \mathrm{~mm}$. 

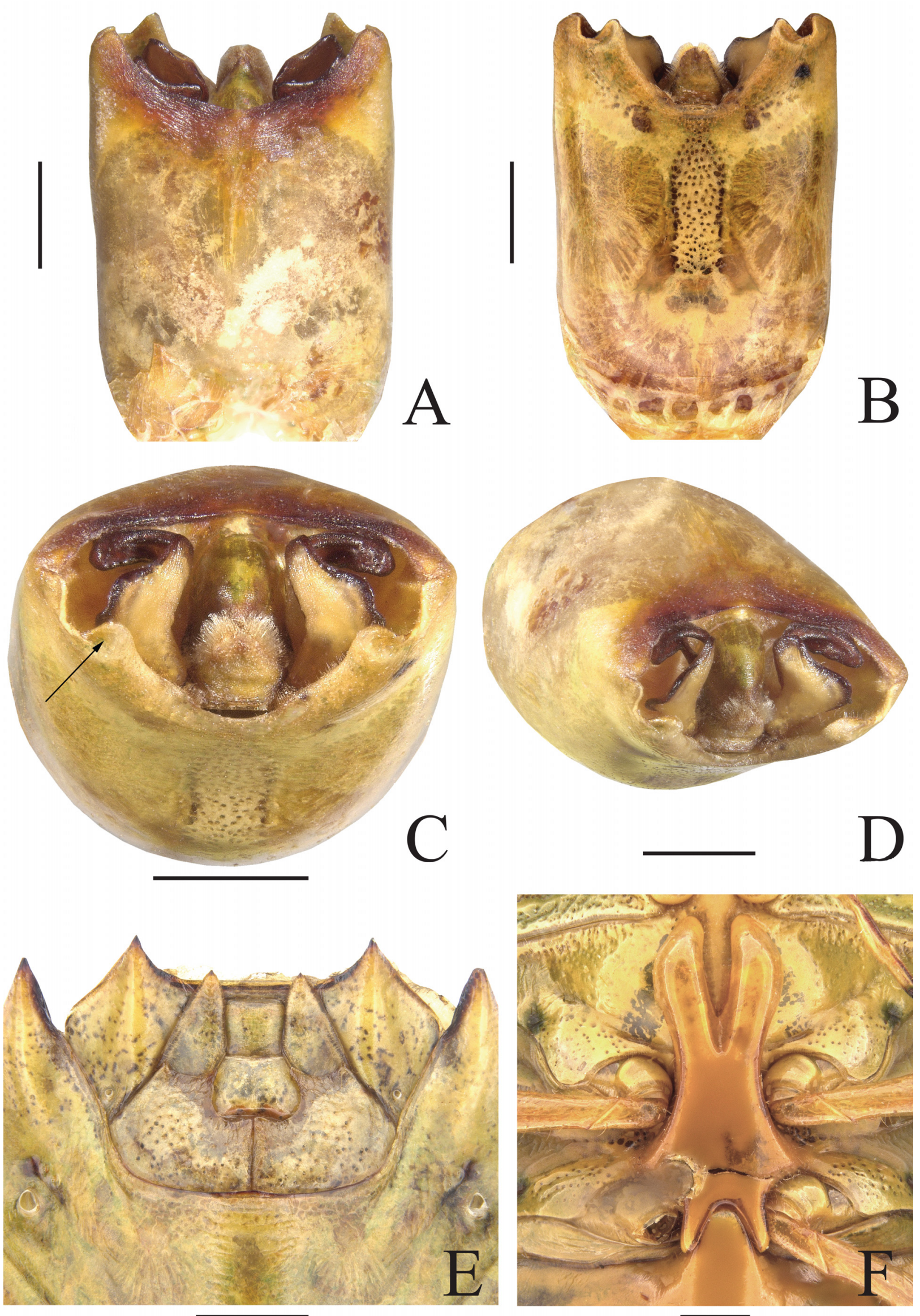

Figs 19A-F. Hypoxys stysi sp. nov. A-D - pygophore in dorsal, ventral, posterior and posterolateral view, respectively; E - genital plates; F - metasternal process. Arrow indicates expansion of the ventral rim with a lateral excavation. Scale bars $=1 \mathrm{~mm}$. 

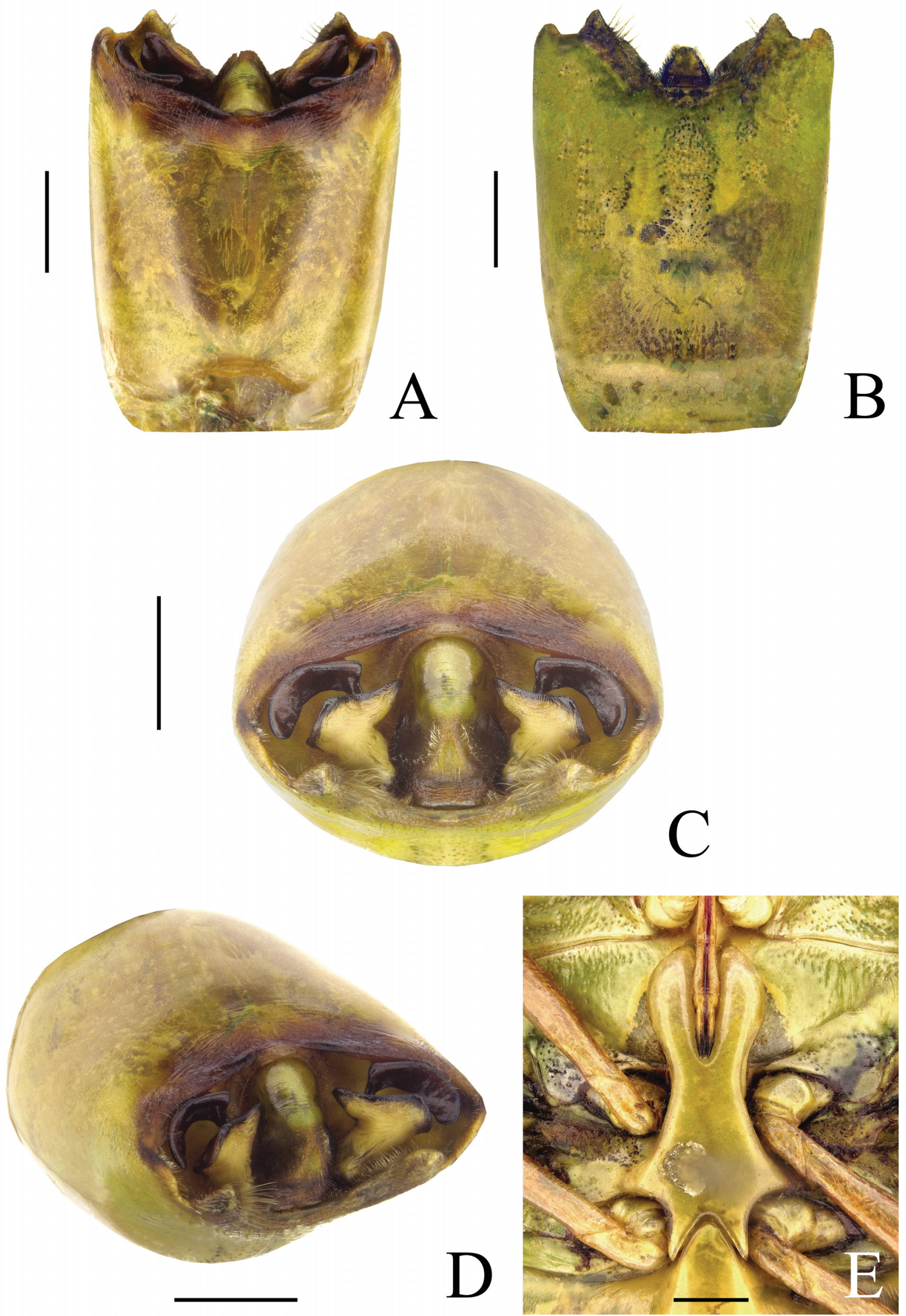

Figs 20A-E. Hypoxys venustus sp. nov. A-D - pygophore in dorsal, ventral, posterior and posterolateral view, respectively; E - metasternal process. Scale bars $=1 \mathrm{~mm}$. 

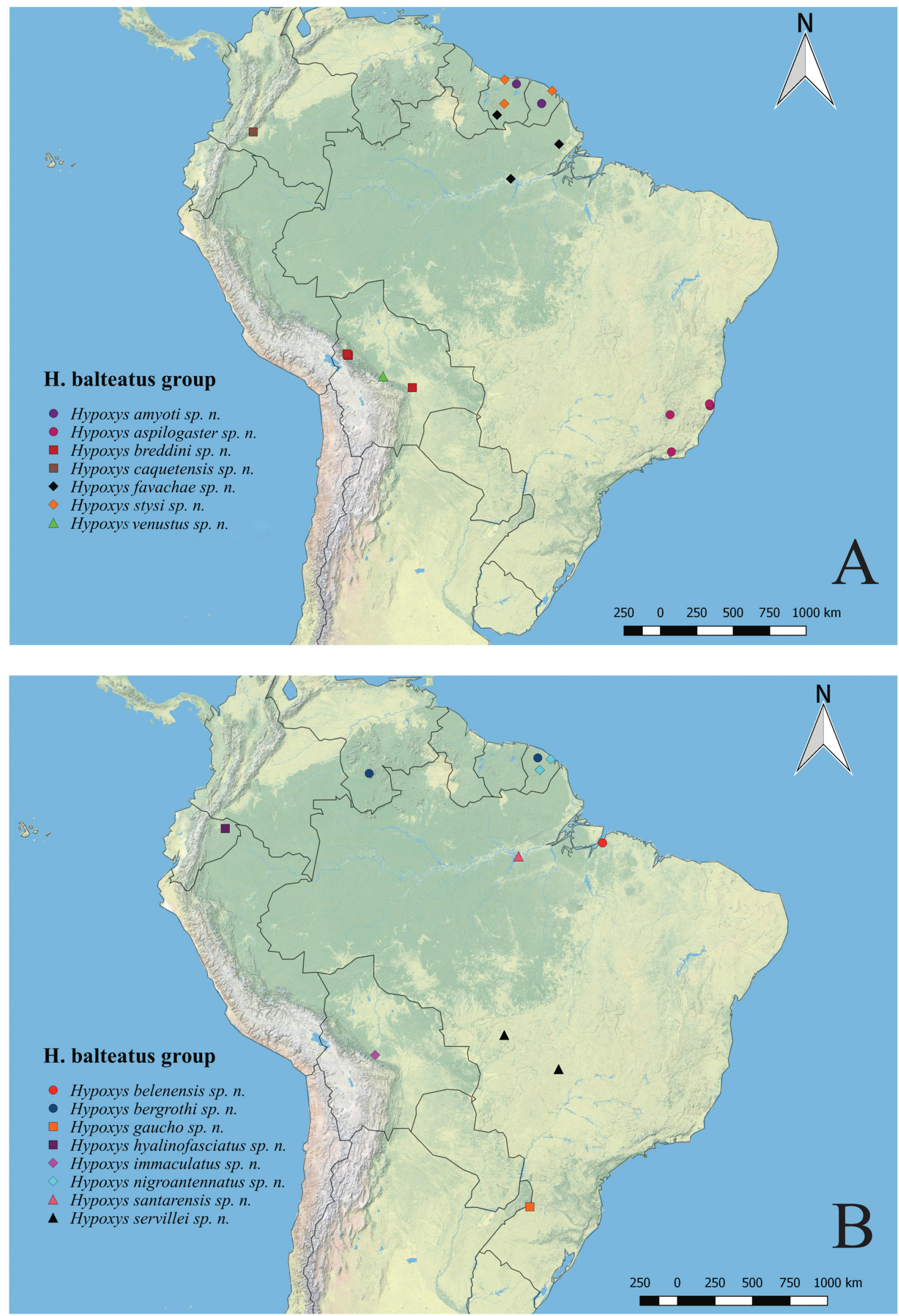

Figs 21A-B. Occurrence maps of the sixteen new species of the Hypoxys balteatus species group. 
apices clearly below imaginary line tangent to apices of abdominal segment VII.

Measurements $(\mathrm{n}=3$; mm). Total length 15.3-18.1; head length 1.3-2.2; head width 3.1-3.5; pronotum width 9.9-11.4; abdomen width 7.7-9.0; length of antennomeres: I - 0.9-0.9 (no span); II - 1.5-1.7; III - 1.0-1.4; IV 3.7-3.8; V - missing; scutellum length 7.2-8.1; scutellum width 5.3-6.4; pronotum length 3.0-3.4.

Differential diagnosis. For the female genitalia see differential diagnosis of $H$. amyoti sp. nov.; for the males see differential diagnosis of $H$. amyoti sp. nov.

Etymology. Named after the Czech entomologist Pavel Štys (1933-2018). Pavel was an eminent specialist in morphology and taxonomy of Heteroptera and a great person. Distribution (Fig. 21A). Suriname: Coronie, Sipaliwini; French Guiana: Cayenne.

\section{Hypoxys venustus sp. nov. (Figs 5E-F, 20A-E, 21A)}

Material examined. Holotype: BOLIVIA: Cochabamba: Villa Tunari, Chapare / ii.1992 / G. Castillo leg. (USNM).

Diagnosis. Antennae reddish. Antennomere II longer than III. Pronotum with smoky stripe reaching posterior margin. Thoracic and abdominal pleurites and sternites with black spots (Fig. 5F). Anterior excavation of metasternal process harboring fourth and third rostral segment (Fig. 20E). Male genitalia. Pygophore (Figs 20A-D). Posterolateral angles developed, straight, rounded (Fig. 20A) not reaching level of projections of ventral rim (Fig. 20B). Superior process of genital cup parallel to dorsal rim, long, reaching posterolateral angles, slightly concave medially; inner (proximal) part truncate, ventral angle projected in dentiform process, adjacent to this angle emerges carina almost parallel to this process; outer (distal) part tonguelike (Figs 20C,D). Paramere with two lobes; anterior lobe triangular, developed, and directed to base of proctiger; lateral and dorsal lobes short and rounded (Figs 20C,D). Proctiger with tufts of short setae along lateral excavation; posterior face triangular (Figs 20C,D). Ventral rim with expansion triangular, distally blunt, ventrolateral side with broad striated excavation, dorsal side without brown spot; apices clearly surpassing level of posterolateral angle (Fig. 20B). Female genitalia. Unknown.

Measurements $(\mathrm{n}=1$; mm). Total length 17.8 ; head length 1.8; head width 3.5 ; pronotum width 11.7 ; abdomen width 9.0; length of antennomeres: I - 0.9; II - 1.7; III 1.6; IV - 4.3; V: missing; scutellum length 7.6; scutellum width 6.3 ; pronotum length 3.5 .

Differential diagnosis. See differential diagnosis of $H$. hyalinofasciatus sp. nov.

Etymology. Named for the bright colors of the specimen (Latin venustus = beautiful, pleasant); adjective.

Distribution (Fig. 21A). Bolivia: Cochabamba.

\section{Acknowledgements}

The authors thank the curators of the above-mentioned collections, David Rider and Petr Kment for valuable comments. This study was in part financed by the Coor- denação de Aperfeiçoamento de Pessoal de Nível Superior-Brazil (CAPES) and Conselho Nacional de Desenvolvimento Científico e Tecnológico (CNPq). (MTSM and BMN: CNPq/CAPES 440627/2015-0 PROTAX; JAMF: CNPq 311345/2018-2).

\section{References}

ALMEIDA F. R. A., NUNES B. M. \& FERNANDES J. A. M. 2018: A new genus and new species of Edessinae (Hemiptera: Heteroptera: Pentatomidae). Zootaxa, 4377 (2): 254-268.

AMYOT C. J. B. \& SERVILLE A. 1843: Histoire naturelle des insects. Hémiptères. Cuvrage accompagné de planches. Librairie encyclopédique de Roret, Paris, lxxvi +675 pp, 12 pls.

CAMPOS B. B., NUNES B. M., BITAR M. V. S. \& FERNANDES J. A. M. 2020: Description of a new group of species of Edessa Fabricius, 1803 (Hemiptera: Pentatomidae: Edessinae) with translucent spot on hemelytra. Zootaxa 4810 (1): 131-142.

CORREIA A. O. \& FERNANDES J. A. M. 2016: Grammedessa, a new genus of Edessinae (Hemiptera: Heteroptera: Pentatomidae). Zootaxa 4107 (4): 541-565.

DUPUIS C. 1970: Heteroptera. Pp. 190-208. In: TUXEN S. L. (ed.): Taxonomist's Glossary of Genitalia of Insects. Munksgaard, Copenhagen.

EGER J. E. 2021: Graziaedessa anastrephae (Heteroptera: Pentatomidae: Edessinae) a new genus and species collected in Multilure fruit fly traps baited with ammonium acetate and putrescine. Zootaxa 4958 (1): 643-648.

ELY E SILVA E. J., FERNANDES J. A. M. \& GRAZIA J. 2006: Caracterização do grupo E. rufomarginata e descrição de sete novas espécies (Heteroptera, Pentatomidae, Edessinae). Iheringia, Série Zoologia 96 (3): 345-362.

FABRICIUS J. C. 1803: Systema rhyngotorum secundum ordines, genera, species, adjectis, synonymis, locis, observationibus, descriptionibus. Brunsvigiae, $335 \mathrm{pp}$.

FERNANDES J. A. M. 2010: A new genus and species of Edessinae from Amazon Region (Hemiptera: Heteroptera: Pentatomidae). Zootaxa 2662: 53-65.

FERNANDES J. A. M. \& CAMPOS L. D. 2011: A new group of species of Edessa Fabricius, 1803 (Hemiptera: Heteroptera: Pentatomidae). Zootaxa, 3019: 63-68.

FERNANDES J. A. M. \& van DOESBURG P. H. 2000a: The E. dolichocera group of Edessa Fabricius, 1903 (Heteroptera: Pentatomidae: Edessinae). Zoologische Mededeelingen (Leiden) 73: 305-315.

FERNANDES J. A. M. \& VAN DOESBURG P. H. 2000b: The E. beckeri-group of Edessa Fabricius, 1803 (Heteroptera: Pentatomidae: Edessinae). Zoologische Mededeelingen (Leiden) 74: 143-150.

FERNANDES J. A. M. \& VAN DOESBURG P. H. 2000c: The E. cervusgroup of Edessa Fabricius, 1803 (Heteroptera: Pentatomidae: Edessinae). Zoologische Mededeelingen (Leiden) 74: 151-165.

FERNANDES J. A. M., vAN DOESBURG P. H. \& GREVE C. 2001: The E. collaris-group of Edessa Fabricius, 1803 (Heteroptera: Pentatomidae: Edessinae). Zoologische Mededeelingen (Leiden) 75: 239-250.

FERNANDES J. A. M., NASCIMENTO A. T. S. \& NUNES B. M. 2018: Revision of Pygoda Amyot and Serville, 1843 stat. rest. (Heteroptera: Pentatomidae: Edessinae) with description of four new species. Zootaxa 4466 (2): 205-232.

FERNANDES J. A. M. \& SILVA V. J. 2021: A new species group to Edessa, the E. ovina group, with description of a new species (Heteroptera: Pentatomidae: Edessinae) from Brazil. Zootaxa 4958 (1): 628-642.

KMENT P. \& VILÍMOVÁ J. 2010: Thoracic scent efferent system of Pentatomidae (Hemiptera: Heteroptera): a review of terminology. Zootaxa 2706: 1-77.

KIRKALDY G. W. 1909: Catalogue of the Hemiptera (Heteroptera) Vol. I: Cimicidae. Felix L. Dames, Berlin, xl +392 pp.

NASCIMENTO D. A., MENDONCCA M. T. S. \& FERNANDES J. A. M. 2017: Description of a new group of species of Edessa (Hemiptera: Pentatomidae: Edessinae). Zootaxa 4254 (1): 136-150.

NUNES B. M., CAMPOS L. D., MENDONCA M. T. S., CUNHA E. V. P. \& FERNANDES J. A. M. 2020: Revision of Hypoxys Amyot 
and Serville, 1843 stat. rest. (Heteroptera Pentatomidae). Zootaxa 4742 (3): 401-441.

NUNES B. M., WALLNER A. M. \& FERNANDES J. A. M. 2019: Anisoedessa, a new genus of Edessinae (Hemiptera: Heteroptera: Pentatomidae) and considerations on Edessinae relationships based on cladistic analysis. Arthropod Systematics and Phylogeny 77 (2): 215-237.

QGIS DEVELOPMENT TEAM 2016: QGIS Geographic Information System. Open Source Geospatial Foundation. Available from: https:// www.qgis.org/pt_BR/site/forusers/visualchangelog212/index.html. (Accessed 12 January 2018).

SANTOS B. T. S., NASCIMENTO A. T. S. \& FERNANDES J. A. M. 2014: Proposition of a new species group in Edessa Fabricius, 1803 (Hemiptera: Heteroptera: Pentatomidae: Edessinae). Zootaxa 3774 (5): 441-459.

SANTOS B. T. S., SILVA V. J. \& FERNANDES J. A. M. 2015: Revision of Ascra with proposition of the bifida species group and description of two new species (Hemiptera: Pentatomidae: Edessinae). Zootaxa 4034 (3): 445-470.
SILVA V. J. \& FERNANDES J. A. M. 2012: A new species group in Edessa Fabricius, 1803 (Heteroptera: Pentatomidae: Edessinae). Zootaxa 3313: 12-22.

SILVA V. J., NUNES B. M. \& FERNANDES J. A. M. 2013: Paraedessa, a new genus of Edessinae (Hemiptera: Heteroptera: Pentatomidae). Zootaxa 3716 (3): 395-416.

STÅL C. 1872: Enumeration Hemipterorum. Bildrag till em förteckning öfver alla hittilis kånda Hemiptera, jemte systematiska meddelanden. 2. Kongliga Svenska Vetenskaps-Akademiens Handlingar, Ny Följd 10 (4): 1-159.

THOMAS D. B. 1994: Mediocampus, a new stinkbug genus from the Dominican Republic (Insecta: Heteroptera: Pentatomidae). Annals of Carnegie Museum 63 (3): 257-261.

WALKER F. 1868: Catalogue of the specimens of Heteropterous Hemiptera in the collection of the British Museum. Part III. Trustees of the British Museum, London, pp. 418-599.

ZHOU Y.-Y. \& RÉDEI D. 2020: From lanceolate to plate-like: Gross morphology, terminology, and evolutionary trends of the trichophoran ovipositor. Arthropod Structure and Development 54 (100914): .1-29. 